\title{
La responsabilidad civil
}

automovilística y el

aseguramiento obligatorio y voluntario: un estudio en el Derecho colombiano y español ${ }^{1}$

Raquel Ceballos Molano ${ }^{2}$

1 Este es un resumen ejecutivo del trabajo de tesis presentado por la Doctora Raquel Ceballos Molano que obtuvo la maxima calificación. Sobresaliente cum laude por unanimidad del Jurado.

2 Abogada, Universidad Libre, Colombia. $\mathrm{PhD}$ en Derecho General de la Universidad Carlos III de Madrid- España. Especializada en Negociación y Contratación Internacional de la Universidad del Valle. Profesora de la Universidad del Valle y Directora de los Postgrados en Administración Pública de la Facultad de C. de la Administración. Miembro del Comité de Propiedad Intelectual de la Universidad del Valle. Miembro del Instituto de Responsabilidad Civil y del Estado de Cali.

Recibido: Septiembre 2005

Aceptado: Diciembre 2005 
Este trabajo de tesis ${ }^{3}$ comprende un estudio de derecho comparado de las instituciones de responsabilidad civil extracontractual y aseguramiento obligatorio y voluntario de la responsabilidad civil del automóvil en los ordenamientos jurídicos colombiano y español, con referencias extendidas al Derecho comunitario europeo.

No hay discusión en reconocer que el avance del vehículo a motor, a partir del siglo XIX, a la par de mayor confort y rapidez, ha venido a consti- tuir una verdadera amenaza para el hombre, con daños a las personas y pérdidas de bienes. Es sabido que la conducción y utilización del automóvil, es una actividad, aunque lícita de gran peligrosidad no solo para conductores sino también para ocupantes y peatones, todos potenciales víctimas de daños, como lo demuestran en Colombia los datos crecientes de muertes y lesionados en accidentes de tránsito ${ }^{4}$.

En la causación de daños, la del

3 Al presentar los resultados finales de esta memoria para obtener el grado de Doctora en Derecho, en el Departamento de Derecho Privado de la Universidad Carlos III de Madrid, es preciso hacer un reconocimiento a los miembros del Instituto de Derecho y Economía de la Universidad Carlos III de Madrid, en cabeza de sus Directores Dr. D. Santos Pastor Prieto y Dr. D. David Camino, quienes me acogieron y brindaron todo el apoyo logístico e intelectual para desarrollar, durante mis estancias como profesora visitante y estudiante de doctorado, tanto el trabajo de tesina en el período 1995-1998 como el de tesis en 2002. A mi Director de tesis Dr. D. Rafael Illescas Ortiz y a esta casa mis agradecimientos, igualmente a la Universidad del Valle que me concedió, como docente nombrada, comisión ad honoren para realizar mis estudios de doctorado.

4 En Colombia es el Fondo de Prevención Vial Nacional quien desarrolla políticas de prevención de accidentalidad. Esta entidad se creó, en 1995 con el apoyo de catorce compañías de seguros privadas y dos ofíciales; el Fondo de Prevención Vial Nacional en concordancia con lo dispuesto en el art. 244 de la Ley 100 de 1993 (Ley de seguridad social), y el art. 13 del Decreto 1813 de agosto 3 de 1994. FONPREVIAL es un organismo privado, sin personería jurídica al que se destina el $3 \%$ de las primas recaudadas por las aseguradoras que expiden el seguro obligatorio de daños corporales causados a las personas en accidente de tránsito y de los aportes que eventualmente realizan algunas entidades; se encarga de llevar los diagnósticos de la accidentalidad, coordinar campañas de prevención y creación del Registro Unico de Accidentes; (GALINDO, Jorge A. "Accidentalidad vial en Colombia. Como prevenirla", en Revista Fasecolda, n 81, septiembre 1996). El Fondo de Prevención Vial, es también patrocinado por la Unión de Aseguradores Colombianos - Fasecolda, entidad que presta una importante colaboración con la revista Fasecolda y sus bases bibliográficas en la difusión y compilación de legislación, doctrina y jurisprudencia sobre el Derecho de seguros en general. 
automóvil es una de las que más perjuicios causa en personas y bienes ${ }^{5} \mathrm{y}$, por consiguiente, la responsabilidad civil derivada de la actividad de las cosas peligrosas, demanda respuestas ${ }^{6}$ que vinculan tanto instituciones del Derecho privado, en las áreas del De- recho civil y mercantil, e igualmente del Derecho público, con el Derecho Constitucional, Penal y Procesal, disciplinas todas en las que se integra el Derecho de responsabilidad civil y seguro de los accidentes de automóvil $^{7}$, el cual es identificado por un sec-

5 En la actualidad en Colombia, la accidentalidad vial es un grave problema de salud pública, que demanda respuestas de los operadores jurídicos por la mortalidad y lesionamientos que presenta, realidad opacada por la situación de violencia armada que viene padeciendo el país. (Fuente de datos. Fonprevial. Accidentalidad vial en Colombia- Resumen 2000, julio 2001) - En los datos históricos del Fondo de Prevención Vial, Resumen 1994- 1995, 1996, 1997, 1998 y 1999, "se muestra que, durante un periodo de diez años de conflicto armado (1987- 1996) fallecieron 15.000 personas, mientras que las víctimas mortales por accidentes de tránsito fueron 57.000, o sea, 3,8 veces más que en el conflicto armado".. Vid PERDOMO M, Mónica Esperanza. "Muertes por accidente de tránsito", en Forensis 2000. Datos para la Vida, septiembre 2001, p 144-165.

6 En búsqueda de respuestas de prevención, las estadísticas presentadas por el Director ejecutivo del Fondo de Prevención Vial, GALINDO, Jorge Alberto. "El alcohol y la accidentalidad vial", en Revista Fasecolda, no 88, abril-junio, 1998, p 3739, señala que: "son alarmantes las cifras de muertos y heridos que deja la accidentalidad vial en Colombia. Solo en 1997 perecieron más de 7.600 personas (equivale a la caída diaria de un avión con 20 ocupantes sin sobrevivientes)". Agrega, a renglón seguido que" Del total de víctimas $80 \%$ son hombres y $20 \%$ mujeres. El 90\% de los accidentes se presenta en las áreas urbanas, pero los accidentes en carretera son más severos."

Continua anotando que en ciudades como “... Bogotá el 70\% de lo muertos en accidentes de tránsito son peatones. Más del $50 \%$ de ellos tenía alcohol en la sangre". En los accidentes por alcoholemia, puede tenerse como factor contributivo el muy alto grado de alcohol en los licores colombianos, especialmente en aguardientes y rones, y que no se produce cervezas sin alcohol, a pesar los generosos consumos de la población. Igualmente, para 1999 se mantiene el índice de mortalidad, “(...) en 1999 murieron 7.026 colombianos en accidentes de tránsito (5 veces más víctimas que las producidas por el conflicto armado). Además 52.346 personas fueron gravemente heridas, muchas de ellas con secuelas de incapacidad permanente. Pero lo más dramático del problema es que la mitad de las víctimas corresponde al rango de edad comprendido entre 15 y 34 años. La cruda realidad es que se está afectando a la gente joven, al futuro del país."- Así lo plasma el informe: Accidentalidad Vial en Colombia 1999. Fondo de Prevención Vial. Santafe de Bogotá, 2000.

7 PINTOS AGER, Jesús. Baremos, seguros y derecho de daños. Madrid: Instituto de Derecho y Economía- Universidad Carlos III de Madrid, 2000, p 25-35, en la introducción de su obra, anuncia que "Tres son al menos, las áreas del Derecho que 
tor doctrinal ${ }^{8}$, con gran propiedad, como Derecho de Daños o Derecho de Accidentes denominado así por las modernas doctrinas economistas.

confluyen en esta materia. Inicialmente podría pensarse que la reparación del daño derivado de accidentes es una cuestión puramente civil. Ahora bien, si se tiene en cuenta que gran parte de los escenarios en los que estos tienen lugar se ven afectados por relaciones contractuales en las que intervienen empresas - muy especialmente las relacionadas con los transportes terrestres, marítimos y aéreos -, la cuestión deviene de interés para el Derecho mercantil. La atracción ejercida por esta rama del Derecho privado es patente en la investigación y en las publicaciones existentes, y a ello no es ajena la cantidad de supuestos en los que concurren contratos de seguro, voluntario u obligatorio. Además, la nada secundaria necesidad de que los mecanismos necesarios para que el derecho de la víctima frente al causante se convierta en una realidad tangible que funcione adecuadamente, requiere habitualmente la intervención judicial y da entrada al Derecho procesal. Este se suma así a las áreas del Derecho civil y Derecho mercantil. Y añadimos nosotros, la relación con el Derecho penal, cuando la conducta causante del accidente automovilístico se tipifica como delito de homicidio culposo o lesiones culposas.

8 Definido también como Derecho de accidentes, sobre todo en la doctrina moderna anglosajona, y en la literatura de análisis económico del derecho en general. Sobre esta importante teoría vid CALABRESI, Guido. The Cost of Accidents (A Legal and Economic Analysis). Trad. de Joaquín Bisbal. El coste de los accidentes. Análisis económico y jurídico de la responsabilidad civil. Barcelona: Ariel, 1984; PASTOR PRIETO,Santos. Sistema Jurídico y Economía. Una introducción al Análisis Económico del Derecho. Cap. VII. Madrid: Tecnos, 1989, p155, al efecto del término "Derecho de Accidentes", precisa en su importante obra sobre esta materia, que "debe entenderse en el sentido de abarcar los temas habitualmente comprendidos al tratar de la responsabilidad civil o responsabilidad extracontractual". PINTOS AGER, Jesús. Baremos, seguros y ...op.cit., p 25 y ss; del mismo autor su novedoso trabajo de tesis, Responsabilidad civil y reparación sin culpa. Un análisis jurídico y económico de las alternativas globales y las reformas parciales mediante baremos. Director, Santos Pastor Prieto.Tesis doctoral leída en Getafe: Universidad Carlos III de Madrid, Departamento de Derecho Privado y de la Empresa, 1997, 548 p, analiza desde la perspectiva del análisis económico del derecho, la última reforma de la Ley del Automóvil de España y la conveniencia o no de la introducción del sistema baremado indemnizatorio para daños corporales; en ella, adopta la denominación "Derecho de accidentes" para referirse "de modo global a todo el subconjunto del sistema jurídico público y privado encargado del control del riesgo" y reserva el término "Derecho de Daños" para "los remedios privados de indemnización o compensación del daño - sistemas de responsabilidad civil y de reparación sin culpa, con la gran variedad de opciones mixtas que combinan elementos de ambos". Esta distinción es importante porque nos permite reconocer en el sistema colombiano de garantías a través del seguro obligatorio de accidentes de tránsito, un típico seguro sin culpa, de creación en el Derecho privado pero inserto en las políticas públicas de la seguridad social (Ley 100/93). Sobre el mismo tema Vid GOMEZ POMAR, Fernando. "El 
EI problema. La accidentalidad vial en los países motorizados ${ }^{9}$ es una de las principales causas de daños corporales y materiales en la población circulante y peatonal, que obliga, al menos en teoría, al propietario o conductor a responder civilmente de sus consecuencias; paradójicamente, también en países con bajo índice de motorización, en vías de desarrollo como en Colombia, donde la accidentalidad vial alcanza niveles de mortalidad que supera la de los países altamente motorizados como el caso de España, y que de forma alarmante y por demás silenciosa, arroja más muertos y lesionados en carreteras y centros urbanos ${ }^{10}$ que los producidos por la violencia socio-política que afronta el país ${ }^{11}$; los datos históricos del Fondo

derecho de accidentes y el análisis económico: Presupuestos e implicaciones básicas", en AA.VV.: Análisis económico del derecho y de la política, Santiago de Compostela, Fundación Alfredo Brañas, 1993, pág.. 83-99. GOMEZ, Fernando y PASTOR, Santos. "El derecho de Accidentes y la responsabilidad Civil. Anuario de Derecho Civil, tomo XLIII, fascículo II, abril-junio, 1989, p 495- 537.BISBAL, Joaquín. "El coste de los accidentes. Análisis económico y jurídico de la responsabilidad civil". Barcelona: Ariel, 1984, p 7. DURAN Y LA LAGUNA. Una aproximación al análisis económico del derecho. Granada: Comares, 1992, 209 p.

9 PINTOS AGER, Jesús. Baremos, seguros y ...op.cit., p 40, encuentra que, "los accidentes de circulación constituyen una verdadera sangría. En la Unión Europea mueren unas 45.000 personas cada año y 1,6 sufren lesiones, lo cual sitúa a este tipo de accidentes como la fundamental causa de muerte no natural o accidental, especialmente entre los jóvenes. En España la situación no es menos alarmante, con 16 muertos y 400 heridos diarios. En los 85.558 accidentes con víctimas que se produjeron en 1996 fallecieron 5.483 personas, 33.899 resultaron heridas de gravedad y 90.258 heridas levemente".

10 Podemos ver que la media tiende a incrementarse en los centros urbanos de las principales ciudades como se deduce del siguiente informe "En la ciudad de Cali - la segunda ciudad del país- ocurren aproximadamente 2 mil accidentes por mes, sin contar los que no se reportan, de acuerdo con las estadísticas que maneja el Diagnosticentro Automotor del Valle (...) Los accidentes de tránsito son la principal razón por la cual se ingresa a los servicios de urgencias en los Centros hospitalarios (...). Fuente de Datos: Centro de Investigación en Salud y Violencia-CISALVA- de la Universidad del Valle. 1997. Cali es una ciudad que empezó a motorizarse a partir de 1913, cuando llegó el primer automóvil a la ciudad traído por Don Jorge Zawadzky; (Fuente de información: Así es el Valle del Cauca. Colombia. El país, Cali, 1998, p 23) y, en menos de un siglo, la ciudad, con una población de aproximadamente 2 millones de habitantes, ya presenta una tasa de accidentalidad muy alta, efecto de la violencia en la conducción, exceso de velocidad, alcohol e impunidad que genera la no observancia de las normas de responsabilidad por conductores y peatones.

11 PERDOMO M, Mónica Esperanza. "Muertes por accidente... op.cit., p 144-165 (publicación del Instituto de Medicina Legal y Ciencias Forenses, Fondo de Prevención Vial), señala: "En Colombia durante el año 2000 fallecieron en accidente de tránsito 6.551 
de Prevención Vial Nacional (Resumen 1998), muestran que durante un período de diez años de conflicto armado (período 1987- 1996) fallecieron 15.000 personas, mientras que las víctimas mortales por accidentes de tránsito fueron 57.000 personas, 3,8 veces más que en el conflicto armado.

En el período 1998/2000, el nivel de accidentalidad se mantiene con las siguientes cifras de fallecidos y heridos: $1998,7.595$ personas muertas y 52.965 lesionados; 1999, 7.026 personas muertas y 52.346 lesionados; y 2000, 6.551 personas muertas y 51.458 lesiona$\operatorname{dos}^{12}$.
El alto índice de accidentalidad vial, constituye la segunda causa de muerte en el país y nos ha ubicado en el primer puesto en el mundo ${ }^{13}$, razón por la cual, estos datos nos llevan a la necesidad de estudiar, revisar y analizar como están estructuradas las instituciones de responsabilidad civil extracontractual y los mecanismos de garantías -aseguramiento obligatoriocon los que el Derecho colombiano responde a la demanda judicial de las numerosas víctimas de accidentes de tránsito.

Entonces el problema que plantea la responsabilidad civil automovilísti-

personas, con una reducción estadísticamente significativa $(p=0,00000000)$ de $7 \%$ en comparación con 1999 (7.026), siendo el año con menor número de víctimas fatales del último quinquenio. Sin embargo, la cantidad de personas fallecidas en accidentes de tránsito supera muy por encima el número de personas (1.500) que murieron en 1998 en el conflicto armado de Kosovo." Agrega el informe, "según estadísticas del Ministerio de Salud (Estadística de mortalidad general 1996), el accidente de tránsito a nivel nacional es la novena causa de mortalidad general y la segunda causa de muerte violenta en Colombia".

12 Ibidem

$13 \mathrm{Al}$ respecto, como antecedente histórico, baste, observar y comparar los índices de mortalidad por ejemplo del año 1994 respecto de algunos países del mundo, en los cuales Colombia, con cifras exorbitantes contrastado su bajo índice de motorización, ocupaba - y sigue manteniendo- el primer puesto en muertos por cada $100 \mathrm{mil}$ habitantes, y respecto de España, tiene una cifra de diez (10) veces más el número de muertos $(341,98$ frente a 31.40$)$ totalmente descomunal, para un país con apenas 2 millones y medio de vehículos, frente a aproximadamente 18 millones del parque automotor español en el mismo período, lo que nos ubicó en el primer puesto de índice de mortalidad en accidente de transito.

\begin{tabular}{|l|c|c|}
\hline País & $\begin{array}{c}\text { Muertos por 100.000 } \\
\text { habitantes }\end{array}$ & $\begin{array}{c}\text { Muertos por c/100.000 } \\
\text { vehículos }\end{array}$ \\
\hline Colombia & 18.32 & 341.98 \\
Turquía & 13.70 & 214.00 \\
\hline España & 14.60 & 31.40 \\
Estados Unidos & 15.60 & 20.80 \\
\hline
\end{tabular}

Fuente originaria : Dirección de Tráfico de España. Citada por el Fondo de Prevención vial en Resumen 1994. 
$\mathrm{ca}^{14} \mathrm{y}$ los mecanismos de reparación, desde el ámbito jurídico, lo constituye el hecho de que la legislación de responsabilidad civil extracontractual y de aseguramiento obligatorio, no tiene un cuerpo normativo autónomo, sino que se encuentra disperso en toda la legislación Civil, Penal, Comercial, Código Nacional de Tránsito, y en Decretos y Resoluciones administrativas, además de la doctrina científica y jurisprudencial, pero sin una mayor evolución legislativa, que propenda por la unificación, o al menos por su distinción, frente a las normas generales de responsabilidad, dada la entidad particular de la responsabilidad automovilística. En nuestro criterio, es justo decir que ni el legislativo, ni la jurisprudencia, ni la doctrina colombiana han prestado atención, desde el punto de vista técnico y jurídico a las normas que regulan la responsabilidad automovilística y su aseguramiento obligatorio; los aportes doctrinales son escasos y la normativa dispersa, lo que dificulta la interpretación sistemática de la materia.

La responsabilidad civil automovilística, se asienta en el ordenamiento jurídico colombiano, en la institución de la "responsabilidad por actividades peligrosas" y de la "reparación integra del daño", conjuntamente con su punibilidad en la legislación penal. Esta institución tiene una doble función: la indemnizatoria, junto a la preventiva y punitiva, pero ambas no alcanzan a tener un grado de evolución acorde con los modernos cánones de responsabilidad derivada de la actividad del automóvil, que la separen de las normas generales de responsabilidad civil. También, es preciso, que cada cual conozca anticipadamente las reglas que deberá respetar y las consecuencias de su no observancia ${ }^{15}$, particularmente, en una asunto de tanto acaecimiento como es el de la respon-

En 1998, en el contexto mundial, los índices de mortalidad y morbilidad relacionados con la población y parque automotor por cada 100 mil vehículos, mantiene a Colombia ocupando el primer lugar en morbilidad, con un índice de 291,0 seguido por Corea 80,3 y Turquía 76,8 que paso del segundo al tercer puesto (Fuente de Datos: Accidentalidad vial en Colombia. Resumen 1998. Fondo de Prevención vial, 1999).

14 Los datos estadísticos del Resumen de 1998 del Fondo de Prevención Vial, sobre accidentalidad para Colombia, con una población de 41'176.202 habitantes, 2'603.345 vehículos, índice de motorización de 63.22 veh/100 habitantes, registró a nivel nacional 206.283 accidentes de tránsito, con 7.595 muertos y 52.965 heridos; estas cifras equivalen a un accidente cada 2.5 minutos, un muerto cada 69 minutos y un herido cada diez minutos; (Fuente de Datos: Accidentalidad vial en Colombia. Resumen 1998. Fondo de Prevención vial, 1999).

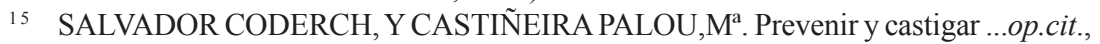
p 11, atribuye a la responsabilidad civil, además de compensar, una función preventiva; aunque en una interpretación cabal, reductivista, el Derecho civil de daños " $n i$ debe ni puede tratar de evitarlos o prevenirlos porque semejante función corresponde al Derecho penal o al administrativo sancionador". 
sabilidad derivada del accidente de tránsito.

Por consiguiente, la propuesta de este estudio es que se considere importante integrar en una ley autónoma la regulación de responsabilidad civil automovilística, con nuevas técnicas de legislación ${ }^{16}$ que desarrollen las posturas jurisprudenciales de las altas cortes sobre criterios de atribución de responsabilidad, en concordancia con una consagración expresa en el Código Penal como delitos contra la seguridad en la circulación vial, tal como se contempla p.e en el ordenamiento jurídico español; en esa normativa se debe estructurar los tipos y sanciones por violación del deber de seguridad que lleven a resultados de muerte o lesiones graves a terceros en el accidente de tránsi- to, para reemplazar la codificación actual, en la que aparece diluida la importancia de dicha responsabilidad en el tipo general de delitos contra la vida, (Lesiones y homicidio culposo por el accidente de tránsito), que debe ser acompañada de un diseño de políticas de prevención de accidentes y respeto por la vida por que no hay una verdadera percepción del ciudadano sobre la necesidad de regular su conducta en el comportamiento vial para preservar la vida de peatones y conductores.

Desde luego, con la propuesta de integración de la normativa, se tendrá un conocimiento cierto de las reglas a que eventualmente se verán sometidos quienes opten por hacer parte de la circulación vial ${ }^{17}$, como propietarios o conductores, o bien como ter-

16 Vid, PUY FRAGA, Pedro. et.al. Análisis económico del derecho y de la política. Santiago de Compostela: Universidad Internacional do Atlántico, 1993, 224 p. Fundación Alfredo Brañas; la propuesta jurídica debe incluir un análisis de las políticas públicas de responsabilidad y aseguramiento obligatorio desde la perspectiva económica; pues cada vez es mayor el número de sectores del orden jurídico a los que se aplica la metodología innovadora del análisis económico del derecho con el objetivo de buscar modelos que superando el enfoque tradicional, ofrezcan explicaciones, de por qué existen determinadas normas jurídicas o instituciones que deben ser modificadas para adaptarlas a una realidad cambiante.

17 Como lo plantea ESPITIA, Victoria Eugenia. "Accidentalidad epidemia de indisciplina", en Salud Coomeva, 2000, p 12-13, todos tienen "su cuota de responsabilidad en el problema $<<$ que debe enfrentarse desde lo público, con las herramientas que se tienen para influir en la sociedad >> ". Debe emprenderse campañas educativas de "respeto a la vida e integridad de las personas", "disciplina vial ", observamiento de carriles, velocidad urbana y rural, señalización, semáforos, paso de cebras, etc., que involucre a conductores, peatones, empresas del transporte, autoridades de tránsito, urbanistas y legisladores de responsabilidad civil y penal; Respecto de las causas de mortalidad en "accidentes" de tránsito, todavía hay la creencia general de tradición catolicista de considerarlos "designios de Dios"; o meramente "fortuitos, producto del azar o de la mala suerte, sin tener en cuenta que son prevenibles"; función del legislador que debe a la par de regular políticas públicas, identificar en la Codificación penal como delito autónomo de negligencia o imprudencia las conductas relacionadas 
ceros perjudicados, en cuanto a derechos y deberes, y la relación vinculatoria que surge entre unos y otros con un tercero, el asegurador, quien bajo el sistema de garantías del seguro obligatorio o voluntario, debe ser el llamado a indemnizar los daños causados en el accidente.

El objeto principal de este estudio es la identificación, análisis y sistematización de la legislación que integra la institución de responsabilidad civil extracontractual y los mecanismos de garantía contenidos en los seguros obligatorio y voluntario del automóvil, a la luz de las últimas reformas que ha sufrido el sistema de responsabilidad y seguro de la Ley del Automóvil del ordenamiento jurídico español y las Directivas del Derecho comunitario europeo, por corresponder ambos sistemas al Derecho continental europeo del cual deriva nuestros estatutos jurídicos.

Se plantea como hipótesis determinar si la atribución de la responsabilidad automovilística, denominada "responsabilidad por el hecho de las actividades peligrosas" del Derecho colombiano, puede ser tenida como una típica responsabilidad por riesgo, cuasi-objetivada, dadas las características similares a las estipuladas en la Ley del automóvil del Derecho español, con unas concretas causales de exoneración. Así mismo, constituye la hipótesis principal comprobar que el aseguramiento obligatorio regulado en el Derecho colombiano, no es un estricto seguro de responsabilidad civil extracontractual por ser contraria su técnica y finalidad a la naturaleza de un crédito de responsabilidad y que deviene en un típico seguro mixto de accidentes personales y de sanidad o salud para cubrir estrictamente los gastos de curación y rehabilitación o muerte e incapacidad de la víctima, respondiendo, prioritáriamente, a las necesidades de financiamiento del sistema de previsión de seguridad social del Estado y las consecuencia económicas que gravaban el sistema hospitalario y la red de urgencias de carácter estatal por la atención a numerosos lesionados de accidentes de tránsito.

Se plantea como hipótesis determinar si la atribución de la responsabilidad automovilística, denominada "responsabilidad por el hecho de las actividades peligrosas" del Derecho colombiano, puede ser tenida como

con la circulación de vehículos de motor que reemplace su actual inclusión en el tipo penal general del "homicidio culposo y lesiones culposas", del capítulo de delitos contra la vida y la integridad personal, artículos 103 a 131 y tampoco aparece incluido en el nuevo capítulo de "los delitos de peligro común o que pueden ocasionar grave perjuicio para la comunidad y otras infracciones", entre los que se tipifica, entre otros, "siniestro o daño de naves", "Disparo de arma de fuego contra vehículo" o "Empleo o lanzamiento de sustancias u objetos peligrosos", conductas que no arrojan la mortalidad que estadísticamente se tiene probada en la accidentalidad vial, pero por no constituir un problema de orden público, el legislador continua desentendido de su identificación en un tipo autónomo. 
una típica responsabilidad por riesgo, cuasi-objetivada, dadas las características similares a las estipuladas en la Ley del automóvil del Derecho español, con unas concretas causales de exoneración. Es importante comprobar si la atribución de la responsabilidad automovilística por "el hecho de las actividades peligrosas", art. 2356 del Derecho colombiano, tiene los mismos presupuestos de la responsabilidad por riesgo cuasi-objetivada de la ley española, hipótesis que planteamos y fundamentamos en la similitud de las características reguladas en el Art. 1 de la Ley de Responsabilidad Civil y Seguro en la Conducción de Vehículos a Motor en el ordenamiento jurídico español.

Así mismo, desde el sistema de garantías de responsabilidad, comprobar que el aseguramiento obligatorio regulado en el Derecho colombiano, no es un estricto seguro de responsabilidad civil extracontractual por ser contraria su técnica y finalidad a la naturaleza de un crédito de responsabilidad y que deviene en un típico seguro mixto de accidentes personales y de sanidad o salud para cubrir mínimamente los gastos de curación y rehabilitación o muerte e incapacidad de la víctima, respondiendo, prioritariamente, a necesidades de financiamiento del sistema de previsión de seguridad social del Estado y las consecuencia económicas que gravaban el sistema hospitalario y la red de urgencias de carácter estatal por la atención de los numerosos lesionados de accidentes de tránsito.
El aseguramiento obligatorio regulado en el Derecho colombiano no corresponde a la dogmática del seguro de responsabilidad civil extracontractual por ser contraria su técnica y finalidad a la naturaleza de un crédito de responsabilidad y que deviene en un típico seguro mixto de accidentes personales y de sanidad o salud para cubrir estrictamente gastos de curación y rehabilitación o muerte e incapacidad de la víctima en forma limitada. No obstante, el SOAT en cuanto a su estructura, se diferencia con el seguro de accidentes personales regulado en el Código de Comercio, pues mientras los seguros de personas, de lo que hace parte el de accidentes personales, responde a principios de cobertura abstracta de necesidades, excepto en cuanto a los gastos médicos, el seguro de responsabilidad como seguro de daños, se ajusta a las exigencias del principio de cobertura de necesidad concreta; el SOAT es un seguro por cuenta de otro que no puede definirse en beneficio de un tercero por su técnica y finalidad contraria a la naturaleza de un seguro de daños y al interés asegurable de garantizar un crédito de responsabilidad, razón por la cual deviene en un típico seguro mixto de accidentes personales y de salud o sanidad, para indemnizar por el valor asegurado, directamente y en forma automática a la víctima del accidente, siendo indiferente que lo sea el propio conductor o un tercero, ocupante o no del vehículo causante del daño por los riesgos de muerte e incapacidad permanente y los gastos de curación y rehabilitación, con coberturas mínimas, sustraí- 
das a cualquier causal de exoneración.

Además, por el contrato del SOAT se contravienen los cánones de la institución de responsabilidad civil extracontractual porque se obliga al asegurador a responder aún bajo supuestos de fuerza mayor, culpa exclusiva de la víctima o de un tercero, desligando el elemento culpabilístico atribuible al conductor o la víctima en la causación del accidente. Es un típico seguro de accidentes sin culpa, no obstante que en caso de accionar por la institución de responsabilidad civil general del art. 2356 del C.C., se niegue la reparación por el daño, cuando en el accidente no ha mediado culpa del conductor, lo que justifica la exoneración de responsabilidad en los supuestos de culpa de la víctima, fuerza mayor o culpa de un tercero, y aún así procede el pago del SOAT por los montos limitados en su cobertura.

De ahí que, se pueda afirmar respecto del aseguramiento obligatorio, técnicamente un seguro de accidentes de personas, que responde a necesidades de financiación del sistema de previsión de la seguridad social destinado a cubrir los costes económicos de las numerosas muerte o lesiones en accidentes de tránsito, verdadera epidemia nacional, que ha venido gravando el sistema general de salud, y la red de urgencias de carácter estatal ${ }^{18}$. Aunque también puede convenirse en que su técnica es de naturaleza mixta de seguro de accidentes y de responsabilidad por la mínima parte que por gastos asistenciales se computan al crédito de responsabilidad civil.

Hay que relevar que el SOAT, contradice la esencia de cualquier seguro de responsabilidad civil cuando se tiene como perjudicado al propio conductor causante del daño o al tercero que por su propia culpa o negligencia sufre el daño. El resarcimiento por daños de los que se es el artífice ${ }^{19}$ solo es viable en seguros de personas, ya

18 VENTURI, Augusto. Los fundamentos cientificos de la seguridad social. Madrid: Ministerio del Trabajo y Seguridad Social, 1995, p 388- 401, expone los medios financieros y el principio de solidaridad general "a cargo del grupo que tenga particular interés en el campo de las prestaciones o particulares responsabilidades en el terreno de las contingencias por las que se suministran aquellas. " Es fácil deducir que con la adopción de este modelo de aseguramiento obligatorio para cubrir básicamente gastos de curación y rehabilitación de la salud, se recupera el presupuesto público, tan precario en países en desarrollo, que se venía destinando a atender los numerosos lesionados por accidentes de tránsito que eran abandonados en las puertas de los hospitales o en las calles donde ocurría el siniestro. Se merma el gasto público que así es trasladado a la masa social de propietarios de automóviles o ciclomotores, quienes por medio del pago de la prima de seguro, están llamados a financiar el aseguramiento obligatorio y se fortalece por tanto el Sistema de previsión de seguridad social destinado a otros riesgos.

19 MEDINA CRESPO, Mariano. El seguro obligatorio de automóviles. Madrid: Lerko, 1994, p 217, desde su punto de vista fueron consideraciones a propósito de la naturaleza del SOA español.. 
que, por los mecanismos de la responsabilidad civil tradicional dejaría de generarse indemnización alguna. Un seguro que cubra los daños autocausados por el agente o la víctima, nunca puede ser un seguro de responsabilidad civil ${ }^{20}$, naturaleza que si puede afirmarse rotundamente del seguro obligatorio español, que excluye tanto al conductor como a las víctimas culpables, por lo cual es un típico seguro de responsabilidad civil.
La justificación tiene asiento en la reconocida ausencia de doctrina científica y trabajos de investigación sobre la materia en nuestra literatura jurídica $^{21}$, que a decir de uno de nuestros principales autores en materia de responsabilidad en general, Gilberto MARTINEZ RAVE: "la falta de unas normas actualizadas, precisas y concretas, abre en este campo del derecho amplias posibilidades a la jurisprudencia y a la doctrina",22, y mayor

20 SÁNCHEZ CALERO, Fernando. Comentarios a la Ley de Contrato de Seguro. Art.76. Madrid: Edersa, 1985, p 660, para el autor en el seguro obligatorio de responsabilidad, sigue siendo válida la opinión tradicional de que el asegurador puede oponer al perjudicado las excepciones que deriven de la naturaleza de la obligación de indemnización contraída por el asegurado, puesto que los hechos impeditivos o extintivos de tal obligación inciden directamente sobre el riesgo que cubre el SOA, para garantizar el crédito de responsabilidad a que debe hacer frente el asegurado, interpretación en concordancia con el art. 1148 del C.C, lo contrario convertiría al seguro obligatorio en un sistema que operaría como un seguro de accidentes.

21 En la literatura jurídica colombiana solo hay una obra relativa a la materia y más desde el punto de vista técnico que jurídico del Dr. OLANO VALDERRAMA, Carlos Alberto. Tratado Técnico- Jurídico sobre Accidentes de Circulación y materias afines. $4^{\mathrm{a}}$ ed. Santafé de Bogotá : Liberia el Profesional, 1996, 794p. Sobre este particular SÁNCHEZ CALERO, Fernando. Curso del derecho privado. Bilbao: Sever, 1961, p 6, en la introducción de la obra relativa al aseguramiento privado, admite en el año de 1961, la dispersión normativa y el abandono por parte de la doctrina española de las normas relativas al seguro, que vino a remediarse con estatutos propios de la Ley de Contrato de Seguro, Ley de ordenación y supervisión de los seguros y Ley de Responsabilidad civil y seguro en la conducción de vehículos a motor, entre las más relevantes; textualmente decía el autor: "la doctrina no ha prestado a esas normas gran atención, aparte de que en ocasiones los temas debatidos lo han sido desde un punto de vista de la técnica actuarial o económica pero no desde el punto de vista jurídico”. Estas razones aducidas, son las mismas que podemos atribuir hoy a la doctrina y jurisprudencia colombiana

22 MARTÍNEZ RAVE, Gilberto. La Responsabilidad Civil Extracontrac-tual en Colombia. 7a. ed. Medellín: Dike, 1993, P 11. Otro gran tratadista de responsabilidad en general es TAMAYO JARAMILLO, Javier. Tratado de Responsabilidad Civil, 4 tomos, Bogotá: Temis, 1999, con la obra más prolífica del Derecho colombiano. 
aún en la institución del contrato de seguro obligatorio del automóvil y su comportamiento dentro del sistema general de los Códigos Civil y de Comercio, sobre los cuales no hay obras en la doctrina jurídica.

Es necesario entonces, desde la investigación jurídica y socio-jurídica avanzar hacia nuevas interpretaciones que, desde el Derecho den respuestas a quienes como víctimas de la actividad del automóvil demandan resarcimiento por los cánones de responsabilidad civil extracontractual, ya que en los procesos penales y civiles, actualmente, no encuentran respuestas oportunas y equitativas para reparar los perjuicios sufridos en accidente de tránsito.

La metodología empleada para la construcción de la hipótesis, es eminentemente teórico-sistemática-descriptiva, se pretende ordenar y analizar toda la legislación vigente en materia de responsabilidad automovilística y seguros en el Derecho colombiano, para demostrar que el sistema de responsabilidad y garantías del aseguramiento obligatorio derivado del accidente de tránsito, no responde a la tipicidad de la institución de responsabilidad civil, sino que por sus notas distintivas, su naturaleza se inscribe en un sistema dual: de una parte un sistema tradicional de responsabilidad sometido al principio de la actividad peligrosa -art. 2356 C.C-para la repa- ración de la totalidad de los daños corporales y de bienes; y de otro un sistema de responsabilidad sin culpa, para la reparación parcial de los daños corporales mediante un seguro mixto de personas, integrado por un seguro de accidentes personales y otro sanitario o de salud que no requiere demostrar grado alguno de culpabilidad por imprudencia o negligencia en la víctima. De otra parte, mediante una metodología comparativa se estudiara la responsabilidad por actividades peligrosas del ordenamiento jurídico colombiano y la responsabilidad por riesgo de la Ley de responsabilidad civil y seguro del ordenamiento español.

Epistemológicamente, la descripción y sistematización de la legislación vigente, constituye un objetivo general de fundamentación dogmática, aclarando que esta tesis versa sobre el estudio de las instituciones de responsabilidad civil y de contrato de seguro, pero limitadas exclusivamente al ámbito automovilístico.

En cuanto a la metodología de la investigación, éste trabajo tiene como fuente el estudio bibliográfico de la ley, la jurisprudencia y doctrina de los principales autores del Derecho de responsabilidad y seguro del automóvil, del aseguramiento obligatorio, así como normativas afines del ordenamiento penal y procesal de los sistemas jurídicos colombiano y español ${ }^{23}$, ambos pertenecientes al derecho continental

23 Entre todos, principalmente DE ÁNGEL YAGÜEZ, Ricardo; GARRIGES DÍAZCAÑABATE, Joaquín. SOTO NIETO, Francisco; DÍEZ PICAZO, Luis; MEDINA CRESPO, Mariano; OLIVENCIA RUIZ, Manuel; PANTALEÓN PRIETO Fernan- 
europeo $^{24}$. Se abordan elementos de conocimiento, impuestos por el marco de la nueva realidad de globalización e internacionalización de las legislaciones y de los países, que propenden a procesos de integración y armonización interdependientes, con efectos económicos, jurídicos y sociales, en cuanto a las personas y los bienes, procesos de los cuales no somos ajenos los países iberoamericanos -que van más allá de su preocupación por ser simples países en vía de desarrollo- precisados a asumir conocimientos del derecho comparado ${ }^{25}$, que posibiliten grandes transformaciones,

do; REGLERO CAMPOS, Luis Fernando; RUIZ VADILLO, P; SANTOS BRIZ, J; CAVANILLAS MUJICA, Santiago; TIRADO SUÁREZ. Francisco Javier; URIA GONZÁLEZ, Rodrigo; YÁNEZ DE ANDRÉS, Aquilino. YZQUIERDO TOLSADA, Mariano; MORILLAS JARILLO, María José; FONT SERRA, Eduardo; SÁNCHEZ CALERO, Fernando; ALONSO SOTO, Ricardo; BARRÓN DE BENITO, José Luis; PINTOS AGER, Jesús; DE ANGULO RODRÍGUEZ, Luis; OSSA G, Efrén; TAMAYO JARAMILLO, Javier. MARTÍNEZ RAVE, Gilberto, OLANO VALDERRAMA, Carlos Alberto.

24 Las instituciones civiles y comerciales del ordenamiento jurídico colombiano tiene su fuente en el Código francés de Napoleón y el Código mercantil español de 1885; a su vez los Códigos españoles, siguieron al Derecho francés; vid, p.e, GABALDÖN GARCÍA, José Luis. "Caracterización y privilegios sobre el buque". Anuario de Derecho Marítimo, Vol. XII, 1995, p 239, y cita 127 en cuanto a los privilegios del buque, explícita que el Código mercantil español sigue también la codificación francesa. En general las doctrinas francesas, aún hoy, son acogidas por el Derecho colombiano.

25 Varios son los propósitos del Derecho comparado, además de perseguir el objetivo de aproximar y armonizar los distintos sistemas jurídicos, también está el mejoramiento de los sistemas nacionales, como lo anota CACERES CORRALES, Pablo J. "Critica constitucional. Del Estado liberal a la crisis del Estado providencia. Bogotá: Banco de La república- p 17-19, "Se propone que la disciplina comparatista obre como apoyo para la perfección del conocimiento de las legislaciones internas y formule soluciones dogmáticas para impulsar su evolución, considerando las determinaciones que otros Estados han estimado procedentes y eficaces para resolver cuestiones similares de la práctica jurídica", la disciplina del derecho comparado realiza esa labor de perfeccionamiento de la legislación interna, agregando además, incluso que "La normativa constitucional de un país es cada vez menos soberana e independiente porque vivimos una época de globalización del sistema capitalista, universal y multisocietario que crea permanentemente reglas universales de comportamiento y principios obligatorios destinados a los ordenes jurídicos nacionales". También respecto de la unificación del derecho, expresa "El fin armonizador de la disciplina comentada es realmente su razón de ser y su objetivo principal". Es de recordar que precisamente en un principio el estudio del derecho comparado, pretendió la unificación en el campo del derecho privado como consecuencia de la necesidad de consolidar las relaciones de intercambio entre los distintos Estados nacionales, por lo cual vemos de suma importancia el intentar este trabajo comparatista con el derecho español de responsabilidad, en esta época de su mayor evolución. 
para eventuales procesos de integración en materias comunes, como las derivadas del derecho de daños, el derecho de la circulación, y el derecho de seguros.

El cuerpo del trabajo se divide en dos partes que integran la sistematización y análisis de las principales leyes, normas, jurisprudencia, directivas comunitarias y doctrina del derecho comparado, español y comunitario europeo de responsabilidad civil y seguro, el sistema colombiano de responsabilidad civil y las garantías indemnizatorias por accidente de tránsito contenidas en el seguro obligatorio -en adelante SOAT - y voluntario del automóvil, mediante la cobertura de responsabilidad civil extracontractual, así:

La primera parte, capítulos I y II, recoge el estudio y análisis de las principales instituciones de responsabilidad civil del automóvil en el derecho comparado; con la observación de no ser todo lo amplio que demandaría el tema, circunscribiendo el estudio a los aportes del derecho español y al sui generis Derecho Comunitario Europeo, que opera como antecedente inmediato de las últimas reformas de la legislación española, derecho comunitario que con carácter de derecho originario debe necesariamente seguir el legislador espa- ñol, a partir de su adhesión a la Unión Europea en 1985, y que comprende las Directivas comunitarias dictadas hasta la fecha, reguladoras de las materias de responsabilidad civil y seguro obligatorio del automóvil en todo el territorio de la Unión Europea, del Espacio Económico Europeo y de los Estados adheridos al Convenio multilateral de garantías que debió ser transpuesto en el ordenamiento jurídico español de responsabilidad civil y seguro del automóvil.

El punto de partida del estudio de derecho comparado, es la legislación, la jurisprudencia y la doctrina española desde la evolución de las normas del Código Civil a partir del art. 1902, 1903. En este aparte, el tema se circunscribe a un limitado análisis de las reformas introducidas por la nueva Ley de Ordenación y Supervisión de los Seguros Privados -Ley 30/95-, en la legislación especial de responsabilidad del automóvil que le dio un nuevo nombre, Ley de Responsabilidad Civil y Seguro en la Circulación de Vehículos de Motor $^{26}$ (LRCSCVM), el nuevo Reglamento de Seguro de Suscripción Obligatoria (R.D. 7/2001) con que se adapta la legislación interna a las Directivas de la Comunidad Europea $^{27}$, y el "Sistema legal de valoración

26 Actualmente desde la aprobación de la Ley de Supervisión de los Seguros Privados, Ley 30 de 1995, de 8 de noviembre, se denomina: Ley sobre Responsabilidad Civil y Seguro en la Circulación de Vehículos de Motor (en adelante LRCSCVM).

27 Vid TIRADO SUÁREZ, Francisco Javier. "La adaptación del seguro del automóvil español a la normativa comunitaria (segunda parte)". En Revista Española de Seguros, $\mathrm{n}^{\mathrm{o}} 49, \mathrm{p} 73$ y ss, también el trabajo compilatorio del mismo autor Directrices de la Comunidad Económica Europea sobre seguros. Madrid: UNESPA, 1979, 269 p. (Unidad de Entidades Aseguradoras y de Capitalización). 
del daño corporal" ${ }^{28}$, este último, a nuestro modo de ver, aunque con criticas al principio de "reparación integra" y al principio de igualdad, es lo más novedoso de las reformas ${ }^{29}$, desarrollado incluso no por iniciativa comunitaria sino del propio legislador español ${ }^{30}$ que ya lo había introducido

28 Incluido en la Disposición Adicional Octava de la Ley 30/95 de Ordenación y Supervisión de los Seguros Privados (LOSSP) anexo a la nueva LRCSCVM/95 un baremo rígido y obligatorio, denominado "Sistema para la valoración de los daños causados a las personas en accidente de circulación". Sobre su adopción Vid MORILLAS JARILLO, María José. "La valoración de los daños: El baremo". En Documentación Jurídica, Coloquios sobre la responsabilidad civil del automóvil, Madrid, núm. 81, p. 205208. Tal como lo explícita la profesora Morillas, a la vista del proyecto de Ley de modificaciones del Texto refundido de la Ley de 24 de diciembre de 1972, "Si un baremo rígido no parecía oportuno tampoco satisfacía la ausencia total de graduación o tasación, que ocasionaba además problemas de previsión a las Compañias del sector, agravando su ya en ocasiones preocupante situación. Tampoco las Directivas comunitarias se atrevían a abordar la cuestión, que si ya de por sí es complicada en el ámbito interno de un país, lo es mucho más en cuanto a su regulación supraestatal, en el marco de la hoy denominada Unión Europea". A renglón seguido, agrega que también "La práctica no supo o no pudo colmar esa laguna de forma eficaz, al menos en cuanto a la reparación de los daños personales. Circularon algunos baremos, pero su uso no se extendió, con lo que vinieron a ser un elemento más de la generalizada falta de uniformidad".

En el mismo sentido los trabajos de DE ÁNGEL YAGÜEZ, Ricardo. Algunas previsiones sobre el futuro de la responsabilidad civil (Con especial atención a la reparación del daño). Madrid: Civitas, 1995, 241 p, que contiene el análisis de las ponencias del Coloquio de Bilbao sobre responsabilidad civil del automóvil; del mismo autor "Sobre la eventual limitación de la cuantía de las indemnizaciones en daños personales derivados de la circulación”. En Documentación Jurídica, Madrid, 1995, núm. 81, p. 127170; "Evaluación del perjuicio corporal en derecho común de la responsabilidad. Los terceros pagadores". Revista Española de Seguros, Madrid, 1988, núm. 56; PANTALEÓN PRIETO, Fernando. "Los baremos indemnizatorios en la valoración de los daños a las personas". Documentación jurídica, Madrid, 1995, núm. 81, p 171204; "Los baremos vinculantes en daños corporales". En Revista de Responsabilidad Civil, Circulación y seguro, 1995; ILLESCAS RUS, Angel Vicente. "La cobertura obligatoria de los daños y perjuicios ocasionados por vehículo dirigido por conductor no autorizado". En Documentación jurídica, Madrid, 1995, núm. 81, p 281- 349.

Incluso, hay voces que piden la extensión del baremo a otros campos del derecho de responsabilidad civil para la valoración del daño personal, incluyendo el ámbito penal. Desmarcada del derecho comunitario, junto a otras reformas introducidas que obedecen a la propia evolución de sus instituciones y del interés de convergencia con los países del Espacio Económico Europeo, entre ellas, la regulación de la actividad aseguradora, el libre establecimiento, el placet o licencia única para operar en cualquier país del EEE, la protección al tomador, el defensor del asegurado, etc. 


\section{como un conjunto de normas con ca- rácter dispositivo ${ }^{31}$ pasando a ser im-}

31 Con Sentencia del Tribunal Constitucional 181/2000, del 29 de junio, (BOE núm. 180, de 28 de julio de 2000) que resolvió las demandas de inconstitucionalidad, se estimó parcialmente las cuestiones de inconstitucionalidad, para los "perjuicios económicos" derivados de "culpa relevante y judicialmente declarada como se desprende del fallo que dice "(...) son inconstitucionales y nulos, en los términos expresados en el último fundamento jurídico de está Sentencia, el inciso final $<<$ y corregido conforme a los factores que expresa la propia tabla $>>$ del apartado c) del criterio segundo (explicación del sistema), así como el total contenido del apartado letra B) $<<$ factores de corrección $>>$, de la tabla $V$, ambos del Anexo que contiene el $<<$ Sistema para la valoración de los daños y perjuicios causados a las personas en accidentes de circulación >> de la Ley sobre Responsabilidad Civil y Seguro de Circulación de Vehículos a Motor, en la redacción dada a la misma por la Disposición adicional octava de la Ley 30/1995, de 8 de Noviembre, de Ordenación y Supervisión de los Seguros Privados." La Ley. Sistema de Seguros, Ramos Especiales del Seguro Terrestre, julio 2000, III$450 / 39$. Este fallo no fue acogido por una tercera parte de los magistrados que hicieron salvamento de voto por discrepar sustancialmente de la interpretación mayoritaria que no obstante en el fundamento 13 de la sentencia en el que se concluye que “(...) la decisión del legislador, en el sentido de establecer un específico estatuto legal para los daños ocasionados en el ámbito de la circulación de vehículos a motor, no pude tacharse de arbitraria y, por lo tanto, privada objetivamente de toda justificación racional, por lo que no vulnera, considerada en su globalidad (el subrayado es nuestro, para resaltar que luego estiman la vulneración en parte de esa globalidad; contradictorio a la técnica discursiva del fallo) como tal sistema, el principio de proscripción de la arbitrariedad del art. 9.3 de la Constitución”, y de reconocer que la situación jurídica preexistente a la promulgación del baremo era de "inseguridad jurídica y de permanentes agravios comparativos", se trato de solucionar estos problemas con el sistema tabular de cuantificación de daños, basado en una responsabilidad por riesgo o de carácter objetivo, prescindiendo de la idea de culpa del agente causante del daño, con limitación a topes cuantitativos obligación de aseguramiento del riesgo y creación de fondos de garantía de específicos (vid fundamento 11 de la misma sentencia), la nueva jurisprudencia viene a introducir nuevamente un factor de atribución de responsabilidad por culpa relevante que no traía la Ley de responsabilidad del automóvil y muy posiblemente una de las consecuencias prácticas que pueden producirse, como bien lo cita el voto particular del magistrado don Fernando Garrido Falla: "pocas víctimas se consideraran dispuestas a admitir que no ha existido culpa del conductor (del otro conductor, en el caso de colisión de vehículos); se buscarán un Abogado... y un nuevo pleito, con motivo de cada accidente, vendrá a incrementar las largas listas de espera de nuestros juzgados. Lo anterior quiere decir, que vuelve a someterse la atribución de responsabilidad al criterio de la culpa subjetivista. Y con la declaratoria parcial de inconstitucionalidad se cumple la expectativa planteada por PINTOS AGER, en su obra Baremos, seguros y ...op.cit, p 34, predijo tales efectos, respecto de los perjuicios económicos - lucro cesante- y su inconveniencia de incluirlos en la reforma del baremo, a su decir "insensible a realidades que pueden y deben indemnizarse de un modo más individualizado". Tema que aborda muy ampliamente en el Capítulo V. 
perativa su aplicación ${ }^{32}$, en la evaluación y tasación de las obligaciones indemnizatorias de accidentes del automóvil con parámetros igualitarios para el daño corporal, patrimonial o extrapatrimonial, mediante tablas baremadas con máximos y mínimos aplicados al caso concreto de la persona perjudicada en el accidente automovilístico, garantizando mayores cánones de celeridad, igualdad y seguridad jurídica ${ }^{33}$.

Se subraya la importancia de positivar en el Código Penal en forma expresa a la categoría de delito o falta la conducción negligente o temeraria de vehículos y ciclomotores. Se ha elevado como delitos autónomos o faltas, en los artículos 379 a 385 en forma expresa los daños causados por la conducción de vehículos y ciclomotores; moderno derecho de responsabilidad con formulaciones actuales debidas a la recepción de las directrices comunitarias, y a la evolución propia de sus instituciones que para el accidente de tráfico paso de una responsabilidad por culpa subjetiva a una responsabilidad por riesgo, objetiva atenuada a través de la Ley de responsabilidad civil y seguro en la conducción de vehículos de motor (LRCSCVM). Igualmente, el seguro obligatorio español, prevé un sistema indemnizatorio del daño corporal a través de tablas baremadas, introducido en la reciente reforma de la Ley del automóvil, mediante la Disposición adicional octava de

32 MORILLAS JARILLO, M. "La valoración de los daños...op.cit., p. 207, considera lo fundamental el cambio de naturaleza del baremo, de orientativo a obligatorio

33 Con la imposición de este nuevo modelo de reparación en el derecho español, se pretende ofrecer solución a la controversia relacionada con los principios de seguridad jurídica e igualdad, en creciente demanda por las víctimas y responsables de accidentes de circulación; solución cuyas respuestas se enmarcan dentro de los principios rectores de la institución de responsabilidad civil, sobre los cuales la jurisprudencia y la doctrina, se sigue preguntando: ¿ si es posible afirmar que con el baremo español, se está frente a un sistema de administración de justicia "justa e igualitaria" para todas las víctimas de accidentes de tráfico? o si $¿$ con ésta norma de previsión indemnizatoria entran en crisis ciertos principios tradicionales de la responsabilidad civil y se mantiene la relativización del principio de restitutio in integrum? Preguntas para las que se encontrara respuesta, en la nutrida doctrina científica española que se aporta a lo largo del trabajo y que vuelve a ser controvertida a partir de la discutida Sentencia del Tribunal Constitucional 181/2000, del 29 de junio, que vuelve a someter muchos casos a la incertidumbre del quantum indemnizatorio por perjuicios económicos, cuando la causa del accidente es por "culpa relevante" del conductor o por dolo, como se desprende de la Sentencia del Tribunal Constitucional . con la declaratoria parcial de inconstitucionalidad se cumple la expectativa planteada por PINTOS AGER, en su obra Baremos, seguros y ....op.cit, p 34, predijo tales efectos, respecto de los perjuicios económicos - lucro cesante- y su inconveniencia de incluirlos en la reforma del baremo, a su decir "insensible a realidades que pueden y deben indemnizarse de un modo más individualizado". Tema que aborda muy ampliamente en el Capítulo V. 
la Ley de Ordenación y Supervisión de los Seguros Privados, (Ley 30 de 1995, de 8 noviembre) que adoptó un sistema indemnizatorio, en el que destaca la supresión del "libre arbitrio" del juez por la imposición de técnicas de valoración total del daño corporal, patrimonial y extrapatrimonial, con unas concretas causales de exención de la responsabilidad de indemnizar ${ }^{34}$.
La segunda parte, los capítulos III, IV y V, identifican y sistematizan la legislación del Derecho colombiano aplicable a la responsabilidad civil extracontractual derivada del automóvil y de los sistemas de garantías, contenidos en el seguro de responsabilidad civil obligatorio y voluntario. Se parte de la normas generales que estructuran la responsabilidad civil automovilística en

34 También sobre sus ventajas y problemas, y como repercute en la resolución de conflictos en la administración de justicia por responsabilidad civil del automóvil, según la doctrina más reconocida entre ellos ILLESCAS RUS, Angel Vicente. "El $<<$ sistema para la valoración de los daños causados a las personas $>>$ de la Ley sobre responsabilidad civily seguro en la circulación de vehículos a motor: ventajas y problemas", ponencia en Jornada Jurídica sobre la Responsabilidad Civil y la valoración del daño corporal, Madrid, 25 de marzo de 1998, anotaba que no es improductiva la disquisición teórica en torno al "sistema", aunque constituya un mandato positivo que establece "un método de tasación normativa de las indemnizaciones por daños corporales de imperativa e inesquivable utilización por los órganos jurisdiccionales"; algunos órganos jurisdiccionales promovieron cuestiones de inconstitucionalidad ante el Tribunal Constitucional, apoyados por la polémica doctrinal. Los partidarios de la inconstitucionalidad afirman que vulnera los principios de igualdad entre unos y otros perjudicados y respecto de otras víctimas de daños corporales por hechos ajenos a la circulación (art. $14 \mathrm{CE}$ ), conculca el deber del legislador de proteger la vida y la integridad física mediante medidas adecuadas de resarcimiento (art. $15 \mathrm{CE}$ ), impide que los perjudicados puedan hacer valer su derecho efectivo ante los tribunales de justicia (art. $24 \mathrm{CE}$ ) y por que elimina las facultades de valoración de la prueba que están reservadas al poder judicial (art. 117 ce). (Vid XIOL RIOS, Juan Antonio. "Reflexiones sobre el sistema de valoración tasada del daño corporal causado con motivo de la conducción de vehículos de motor". Ponencia presentada en la misma Jornada Jurídica). Otros alegan, su inconstitucionalidad por la vulneración del valor justicia y el principio de interdicción de la arbitrariedad 1.1., 9.3; el de reserva jurisdiccional y tutela judicial efectiva 117.3., p. e., PANTALEÓN PRIETO Fernando. "Los baremos indemnizatorios en la valoración de daños a las personas". En Documentación jurídica, $\mathrm{n}^{\mathrm{0}}$ 81. Madrid, 1995, 81, pág.. 171- 204. De nuevo sobre la Constitucionalidad del Sistema para la Valoración de Daños personales de la Ley sobre Responsabilidad y Seguro en la Circulación de Vehículos a Motor". En Revista La Ley, 4 marzo 1997. PINTOS AGER, Jesús. Responsabilidad civil y reparación sin culpa....op.cit., p 432; del mismo autor Baremos, seguros y .... p 337 y ss, un completo análisis de la reforma introducida con el sistema. DE ÁNGEL YAGÜEZ, Ricardo. Algunas previsiones sobre el futuro de la responsabilidad civil (Con especial atención a la reparación del daño). Madrid: Civitas, 1995, 107- 216 p, recoge en este capítulo los principales comentarios en pro y en contra de la imposición del sistema de valoración legal, con el establecimiento "techos" o topes indemnizatorios en abierta ruptura con el principio tradicional de la "reparación integra". 
la legislación civil, arts. 2341 al 2347 y 2356 del Código Civil; luego la responsabilidad penal consagrada en los art. 109 a 110, 120 a 121 del nuevo Código Penal (Ley 599/2000); y, las normas reguladoras del seguro obligatorio, art.
96 del Código Nacional de Tránsito Terrestre de $1970(\mathrm{CNT})^{35}$, reglamentado luego por el Decreto 1285 de julio 7 de 1973 -ya derogado-adicionado por la Ley 33 de $1986^{36}$, y su D.R. 2544 del 31 de Diciembre de 1987, ya en desuso,

$35 C f r$. Decreto Ley 1344 del 4 de agosto de 1970 -CNT, con el que quiso el legislador acércanos a sistemas avanzados de responsabilidad en el contexto mundial; empezó a regir el 1 de Enero de 1971, y estableció el aseguramiento obligatorio como un seguro de responsabilidad civil, no obstante, al ser reglamentado, resultó ser un estricto seguro de accidentes personales para indemnizar los gastos de curación y recuperación de la salud así como los gastos de entierro y muerte de las víctimas de accidentes de tránsito, a pesar de lo dispuesto en el precepto legal; el art. 96 del CNT que determinó "La vigencia de un seguro que cubra la responsabilidad civil por daños a terceros ocasionados con él, es requisito indispensable para concesión y la conservación de la licencia de tránsito. Para el desarrollo de este artículo, se facultó al gobierno, para que “(...) reglamentará la naturaleza, cuantía y prestación del seguro y la vigencia". La inserción de esta normativa, a nuestro entender, se hizo en forma desafortunada dentro del Capítulo IV Licencia de tránsito, deja entrever, que el legislador aún no se encontraba preparado para abordar su reglamentación, pues salta a la vista su imprecisión, apareciendo como una disposición suelta y fuera de contexto. Prueba de ello, es el Decreto 1285 del 7 de julio de 1973, con que se reglamentó dicho seguro, transcurriendo más de diez años, sin que llegará a operar; su regulación; constituyó letra muerta, tanto para usuarios, conductores y compañías aseguradoras frente a una administración pública desentendida de su puesta en práctica que vino a hacer efectiva después de más de quince años, hasta 1988 y aún hoy sigue siendo muy cuestionada la forma de operación del aseguramiento obligatorio - el SOAT- para brindar real protección de asistencia sanitaria, a las víctimas de accidentes automovilísticos.

36 La Ley 33 de febrero 3 de 1986 (publicada en el D.O. No. 37336 de febrero 6/86), modificó el Código Nacional de Tránsito vigente en la fecha de su expedición, y adicionó por disposición del art. 114, el Capítulo Décimo del C.N.T., en el Título IV Faltas y Sanciones, cuyo texto transcribimos:

Ley 33/86 Art. 114 : “Adiciónase el Título IV del Decreto-Ley 1344 de 1970, con un nuevo capítulo que se denominará: Seguros y Responsabilidad, el cual estará integrado por los artículos 259 a 262 y constituirá el Capítulo X del Código Nacional de Tránsito" Con este artículo, el legislador logró llenar el vació normativo que traía el CNT., al desarrollar con la disposición contenida en el art. 115, el nuevo art. 259 que estructura "el seguro por daños a las personas causados en accidentes de tránsito será obligatorio y el perjudicado tendrá acción directa contra el asegurador". A la par de definir en el artículo 116, nuevo art. 260 del CNT., a quién se obligaba a otorgarlo, delegando en "las compañías de seguros establecidas en el país y que tengan autorización para operar en el ramo de automóviles..." 
que lo modifican o adicionan; el Decreto 1032 de 18 de abril de $1991^{37}$ modificado por el D. 663 de 1993, con que se impone definitivamente el aseguramiento obligatorio de la responsabilidad "por accidentes de tránsito", que repara únicamente, y en forma limitada, los daños corporales patrimoniales, mecanismo de garantía que obliga subsidiariamente a contratar y mantener vigente una "Póliza de seguro de automóviles" de contratación voluntaria en caso de incurrir en responsabilidades por daños a personas y bienes que no están cubiertos por el seguro obligatorio, pues el SOAT es un seguro sin culpa de carácter socializante que deja indemne los mecanismos tradicionales para reclamar judicial o extrajudicialmente, la indemnización correspondiente a la totalidad del daño corporal y del año moral y los que recaen sobre bienes, bienes por la jurisdicción civil o penal.
En cuanto a la dogmática por responsabilidad automovilística, nuestra legislación, se encuentra como en casi todas las legislaciones de derecho continental de tradición romanista, regulada bajo principios del ordenamiento civil y penal, a través de la institución de responsabilidad civil ex delicto o extracontractual, fundada en la teoría del alteren non laedere, que establece el deber de no causar daño a otro y la obligación correlativa de reparar, "al estado anterior al daño" (art. 2341 C.C). La infracción de este deber hace surgir un vínculo entre el dañante y la víctima, un nexo de causalidad nacido a la ocurrencia del daño, que adicionado al principio de la culpa, imperante durante todo el siglo XIX y buena parte del XXI, determinó una responsabilidad por "el hecho de las cosas en actividades peligrosas ${ }^{\prime 38}$. Fruto de profundas transforma-

37 En ejercicio de las facultades extraordinarias conferidas por la Ley 45 de 1990 - cuyo objetivo era la reforma financiera y de la actividad aseguradora del país- se dictó el Decreto 1032/91, que tal como reza su preámbulo "por el cual se regula integralmente el seguro obligatorio de daños corporales causados a las personas en accidente de tránsito", pareciera que implícitamente derogara el Decreto 2544 de diciembre 31 de 1987, más aún cuando en el nuevo Decreto, el art. 35 "REMISION AL REGIMEN GENERAL, somete las cuestiones no previstas a las normas del "Contrato de seguro terrestre en el Código de Comercio y la Ley 45 de 1990", sin referirse al D.2544/ 87, para derogarlo o dejarlo vigente en aquellas materias no reguladas en el D.1032/91; no obstante, en nuestro concepto no hay tal derogación, entendiendo que al no preverlo así la nueva Ley, no por ello puede interpretarse tal efecto, quedando a nuestro entender, eso sí en desuso, al entrar en vigencia la nueva norma del S.O.A.T.

38 Señala el art. 2356 del Código Civil, libro cuarto De las obligaciones en general y de los contratos, Titulo XXXIV "RESPONSABILIDAD COMÚN POR LOS DELITOS Y LAS CULPAS": "Por regla general todo daño que pueda imputarse a malicia o negligencia de otra persona, debe ser reparado por ésta". Son especialmente obligados a esta reparación en forma expresa y enunciativa: "1. El que dispara imprudentemente una arma de fuego. 2. El que remueve las losas de una acequia o cañería, o las descubre en calle o camino, sin las precauciones necesarias para que 
ciones del art. 2356 del Código Civil, a partir de las sentencias de 1935 y $1938^{39}$ se establece un nuevo canon de presunción de responsabilidad aplicable a la actividad del automóvil, con inversión de la carga de la prueba en favor de la víctima.

Aunque la jurisprudencia y la doctrina no son pacificas, coincidimos con el sector que afirma que la responsabilidad por actividades peligrosas enerva una presunción de responsabilidad $^{40}$ derivada de la teoría de responsabilidad por riesgo, que elimina la interpretación tradicional del principio psicológico o moral de la culpa, la "presunción de culpabilidad", e invierte la carga de la prueba en favor de la víctima, bastando para la declaratoria de responsabilidad, la existencia del daño, una relación de causalidad eficiente ligada a la actividad del automóvil y que el daño irrogado no se haya producido por una "causa extraña". De existir esa causa extraña, se reconocen con poder liberatorio, cuatro acontecimientos positivos, que pueden subsumirse en dos, todos externos al obrar del conductor: 1) la fuerza mayor o el caso fortuito -externo a la actividad del ve-

no caigan los que por allí transiten de día o de noche. 3. El que obligado a la construcción o reparación de un acueducto o fuente, que atraviesa un camino, lo tiene en estado de causar daño a los que transitan por el camino"; no obstante, está enumeración no cierra la aplicación a otras actividades como la del automóvil.

39 COLOMBIA. Las tres sentencias que constituyeron la nueva doctrina jurisprudencial de la Corte Suprema de Justicia, de 30 de noviembre de 1935, del 14 de marzo y 31 de mayo de 1938, en las que se sentó la doctrina de inversión de la carga de la prueba en procesos por responsabilidad civil derivada de actividades peligrosas, entre estos, los relativos a accidentes de tránsito; la víctima debe probar únicamente que el daño fue causado en el ejercicio de una actividad peligrosa, en cuyo caso el demandado sólo podrá exonerarse demostrando una "causa extraña"; y esa causa se convierte en exoneración de responsabilidad siempre y cuando corresponda a fuerza mayor, caso fortuito, culpa exclusiva de la víctima o el hecho de un tercero.

40 La presunción de responsabilidad del artículo 2356 del C.C., es una tesis acogida, por los principales tratadista colombianos MARTÍNEZ RAVE, Gilberto. Responsabilidad civil extracontractual en Colombia. $9^{a}$ ed. Medellín: Dike, 1996, p 318- 323 que dedica este aparte, a las "diferencias entre las presunciones de culpa y de responsabilidad"; y el ex magistrado de la Corte Suprema, profesor TAMAYO JARAMILLO, Javier. Tratado de Responsabilidad Civil, t. 2, Bogotá: Temis, 1999, 350 p,. la obra más prolífica del Derecho colombiano; 4 tomos dedicados al estudio de la responsabilidad civil. Coinciden los dos autores en que la presunción de culpa se desvirtúa por el agente con la demostración de diligencia y cuidado, contrario sensu, en la presunción de responsabilidad solo cabe para exonerarse de responsabilidad, demostrar la existencia de una "causa extraña", fuerza mayor o caso fortuito, culpa exclusiva de la víctima o de un tercero y sí estos últimos son los que liberan en la responsabilidad por actividades peligrosas, pues de ella se deduce, una presunción de responsabilidad y no de culpa como se sigue fundamentando en numerosos fallos por lo cual se mantiene la confusión. (Vid Sent. C.S.J mayo 5 de 1999. Rad. Expediente 4978). 
hículo-, 2) la culpa exclusiva de la víctima o el hecho de un tercero, constitutivos de exoneración de la obligación de indemnizar.

Desde este punto de vista, puede afirmarse, como se verá a lo largo del trabajo, que estos eximentes también se predican en otras legislaciones como elementos atenuantes de la denominada "responsabilidad por riesgo", tornándose, en virtud de la naturaleza de la "causa extraña", en un sistema de responsabilidad civil atenuado o cuasi-objetivado que se acerca a los elementos estructurales del sistema español de responsabilidad y seguro del automóvil ${ }^{41}$. Aunque, aclarando que la Ley española ${ }^{42}$ excluye de sus causales de exoneración el caso fortuito, que si consagra la jurisprudencia colombiana; en el sistema de responsabilidad español en cuanto a los daños corporales, la exención de responsabilidad procede si se prueba que fueron debidos únicamente a culpa o negligencia del perjudicado o a fuerza mayor extraña a la conducción o al funcionamiento del vehículo, excluyendo expresamente que no se considera fuerza mayor los defectos de éste-el automóvil- ni la rotura o fallo de algunas de sus piezas o mecanismos

En criterio de la autora, la evolución de la jurisprudencia colombiana en la imputabilidad de responsabilidad civil derivada del accidente automovilístico, pasa de la responsabilidad subjetiva clásica, a un sistema de responsabilidad con inversión de la carga de la prueba, equiparable a los sistemas cuasi-objetivados, pues al estar también fundamentada en la teoría de "la actividad de la cosa peligrosa" que no es más que a "una causalidad jurídi$\mathrm{ca}{ }^{\prime 43}$, que presume de suyo la responsabilidad por la "actividad", que la jurisprudencia mayoritaria la sigue equi-

41 No obstante, lo afirmado, hay que matizar, que el sistema de imputación español de responsabilidad automovilística, no se consagra en las normas del Código Civil, sino en una Ley especial, la LRSCSCVM, que expresamente para los daños corporales regula las causales de exoneración, y acude a la normativa civil en situaciones especificas, como es para la reclamación de los daños a bienes (art. 1902 C.C); circunstancia muy diferentes del sistema colombiano, cuya fuente de creación, no es una Ley especial y autónoma sino de interpretación jurisprudencial (art.2356 C.C.).

42 Vid. El art. 1 Ley de Responsabilidad Civil y Seguro en la Conducción de Vehículos de Motor, Texto Refundido de la Ley 122 de 24 de diciembre de 1962, modificada por la Ley 30/1995.

43 Es doctrina reiterada de la corte, que la causalidad basta para tener por establecida la culpa en aquellos casos en que, atendidas la naturaleza propia de la actividad y las circunstancias precisas en que el hecho dañoso se realizó, la razón natural permite imputar este último a la incuria o imprudencia de la persona de quien se demanda la reparación. 
parando a una presunción de culpa ${ }^{44}$, aunque este técnicamente más asimilada al principio del riesgo, con una presunción de responsabilidad y dos concretas causas de exoneración de esa responsabilidad, que atenúan el rigor de la teoría objetivadora.

En el sentido señalado, la responsabilidad aplicable a los accidentes de vehículos, aunque denominada por la jurisprudencia "por el hecho de las cosas en actividades peligrosas" situada en la infracción del "deber de cuidado del guardián de la cosa”, no es más que un sinónimo de la actividad por el riesgo ${ }^{45}$ que produce la cosa, impregnada de las teorías francesas del siglo $\mathrm{XX}$, pero que atempera todos los elementos para transformarla de una responsabilidad por actividades peligrosas a una típica "responsabilidad automovilística por el riesgo desplegado" que prevea una exoneración de responsabilidad para el agente con un actuar irreprochable, que a pesar de ello sea el "causante" del accidente, en sentido material, bien por culpa o negligencia de la propia víctima o por fuerza mayor extraña a su conducción o el hecho de un tercero como bien se consagra en la legislación española, que tipifica una responsabilidad asentada en el riesgo creado por el vehículo, la cosa inanimada, que por su accionar de peligrosidad puede ocasionar daños por infracción del “deber

44 Sentencia Corte Suprema de Justicia del 5 de mayo de 1999, Rad. Expediente 4978, con ponencia del Magistrado DR. Jorge Antonio CASTILLO RUGELES, aunque ha puntualizado la Corte, que la regla del artículo 2356 del Código Civil apareja una presunción de culpa en contra de quien causa perjuicios con ocasión del ejercicio de aquellas actividades cuya ejecución entraña peligros o riesgos para las personas del entorno, responsabilidad de la cual solamente se exonera en cuanto acredite que el daño sólo pudo tener por fuente cualquier suceso extraño, como la fuerza mayor, la culpa exclusiva de la víctima o la de un tercero. Igualmente que todas las actividades de esa especie, llamadas peligrosas, aparejan "la existencia de una obligación legal de resultado consistente en vigilar esa actividad e impedir que ella, por su propio dinamismo o debido a circunstancias anormales que la rodearon en un momento dado, escape al control de quien de la aludida actividad se sirve o reporta beneficio; luego si en la realización de un daño se demuestra que tuvo influencia causal caracterizada, un hecho de la índole de los que viene haciéndose mérito en estas consideraciones, ello, en términos de ley, es suficiente para tener por probada, por vía de una presunción contenida en aquella disposición, la infracción de la obligación de guarda recién aludida y en su defensa, entonces -a pesar de lo dicho inicialmente de aparejar una presunción de culpa- no puede plantearse con éxito en el terreno de la culpabilidad sino en el de la causalidad (G.J. CCXXXIV. Pág. 260).

45 Como puede verificarse con las notas inmediatamente supra en la jurisprudencia colombiana no es de fácil recibo la teoría de la responsabilidad por riesgo, por asimilarla a una responsabilidad estrictamente objetivada; $y$, sigue fundamentada en la responsabilidad por infracción del deber de cuidado del guardián de la cosa, siguiendo a la doctrina francesa, art. 1384 del C.C. 
de seguridad" o por negligencia en su actuar, sin tener que imputar una responsabilidad por la guarda, sino por el riesgo que desplega el vehículo. Con las sentencias del 30 de noviembre de 1935,14 de marzo y 18 de mayo de $1938^{46}$, la Corte Suprema sentó nueva doctrina jurisprudencial, pasando de la responsabilidad subjetiva o por culpa a la responsabilidad por actividades peligrosas o de presunción de culpa que descarga a la víctima de la obligación de probar la culpa, bastándole sólo probar el daño que sufrió por razón o motivo de la actividad peligrosa, para que el autor -el conductorquedara presumido de responsabilidad y le corresponde al dañante, el conductor, por la inversión de la carga de la prueba, descartar la presunción que pesa sobre él, demostrando que el daño obedece a "una causa extraña", fuerza mayor, caso fortuito o culpa de la propia víctima o de un tercero.

En síntesis, se presume de responsabilidad al que ejerce la actividad peligrosa, criterio objetivador, no pretendido en su momento, pero que bajo nuevas interpretaciones transita por el ámbito de la teoría del riesgo, aunque así no esté reconocido y se resista la jurisprudencia a declararlo; se puede equiparar la adecuación jurisprudencial del art. 2356 del CC., a la naturaleza del sistema de responsabilidad del automóvil del Derecho español con una imputación cuasi- objetivada y un sistema de garantía, excluido obviamente el sistema baremado de reparación del SOA. Aunque también en el ordenamiento jurídico colombiano se acompaña la responsabilidad por actividad peligrosa derivada del automóvil de un seguro obligatorio así sus límites y coberturas sean bajas, consecuencia de las nuevas interpretaciones del moderno Derecho de accidentes o Derecho de daños, que determina a la par de presunciones de responsabilidad, la adopción de sistemas de garantías para protección de las víctimas, que en nuestro ordenamiento cumple el SOAT ${ }^{47}$.

Cumplida la sistematización de la normativa sobre responsabilidad automovilística, se identifican las normas que positivan el aseguramiento obligatorio del automóvil para desarrollar el objeto específico de la investigación, centrado en analizar la naturaleza y estructura del sistema del aseguramiento obligatorio por responsabilidad civil.

En cuanto a las garantías de reparación puede decirse que el legislador colombiano reguló a la par de las reglas de responsabilidad civil ex delicto o extracontractual, un sistema repa-

$46 \quad$ En Gaceta judicial No 1934 y 1936.

47 Aunque solo tenga dos coberturas deducibles de la deuda de responsabilidad civil, las indemnizaciones por Gastos médicos y gastos de entierro y transporte que al ser pagadas por el asegurador, pueden deducirse del quantum a pagar por responsabilidad civil a cargo del conductor o tercero civil responsable, carácter indemnizatorio atribuido a tales coberturas en la legislación civil y comercial del contrato de seguro, que se adoptó en el articulado del Decreto 1032/91, reglamentario del SOAT, modificado por el Decreto 663/1993 (Estatuto financiero). 
ratorio de orden público con criterios del derecho privado, que obliga a la contratación de un seguro de daños corporales a las personas en accidente de tránsito. Este sistema, es un seguro de responsabilidad sin culpa estructurado como un típico seguro de accidentes personales y sanidad, en nuestra opinión una acertada estructura, aunque los topes son bajos y sólo alcanzan a una mínima reparación ${ }^{48}$ por los gastos de curación, de entierro, y una prestación por incapacidad permanente o muerte en forma de seguro de vida. Es un seguro de responsabilidad sin culpa que indemniza automáticamente a la ocurrencia del riesgo asegurado, la muerte o las lesiones en accidente de tránsito, con criterio socializado pero sin el suficiente desarrollo económico, en razón al nivel de riqueza del país y del sector asegurador. Este sistema de reparación, sigue a los países nórdicos, anglosajones y europeos, que han implementado sistemas insertos en los seguros privados o públicos de solidaridad social, según el cual la sociedad como tal o representada en la masa de propietarios o conductores de vehículos, asumen una distribución del riesgo del tráfico imposible de evitar y lo trasladan a un tercero -el asegurador- quien garantiza a la víctima el pago de la indemni- zación por los daños causados, generalmente mediante contratos de seguro obligatorio de responsabilidad civil automovilística, sistemas de garantías muy suficientes que tienden a cubrir la integridad del daño.

De ahí, nuestra hipótesis, al estimar el aseguramiento obligatorio colombiano más que un seguro de responsabilidad civil, un típico seguro de accidentes personales y sanitario, que responde a políticas estatales de orden financiero y de previsión de la seguridad social. Como contrato mercantil está sometido para su ejecución a las disposiciones contenidas en el Código de Comercio para el contrato de seguro de personas, dotado de acción directa para la efectividad de la prestación asegurada; y en el evento de fallecimiento de la víctima, transmite a sus causahabientes tal derecho, conforme a lo rituado en el art. 1042 del C.Co, que permite a los herederos de Ley, recibir la indemnización automáticamente en calidad de beneficiarios, sin tener que iniciar una acción civil de responsabilidad, ni esperar apertura de sucesión o partición de herencia porque sus efectos son asimilables a la designación de beneficiarios a título gratuito en un contrato de seguro de vida. Además goza de la facultad excepcional con que el legisla-

48 TIRADO SUÁREZ, Francisco Javier. "La adaptación del seguro del automóvil español a la normativa comunitaria". En R.E.S, núm 47/48 (4-5T/1986) y 49(1T/ 1987), p 71; respecto de los cambios introducidos en el seguro obligatorio por su adaptación al derecho comunitario, partía de la base que las coberturas indemnizatorias venían siendo irrisorias, de techos muy bajos, así lo cita MEDINA CRESPO, M. El seguro obligatorio...op.cit., p 145. 
dor dotó al contrato de seguro en general, de prestar mérito ejecutivo, una vez transcurre el plazo legal de reclamación - de un mes calendario desde la presentación de los documentos que acrediten el derecho a indemnizar; tampoco le caven exclusiones de ninguna clase, salvo la de pago; es un contrato de seguro que en la practica, facilita a los perjudicados la reparación del daño, en razón a que el asegurador obligatorio indemniza las reclamaciones que se le presentan en forma extrajudicial sin tener que acudir a la vía judicial, o en caso de hacerlo, el causante del daño, el conductor, asegurado o tomador no es más que el punto de conexión, porque la relación jurídica se establece directamente entre el asegurador y la víctima o sus causahabientes.

Desde otra perspectiva, la reparación del daño derivado de la respon- sabilidad civil automovilística, tanto en el sistema de responsabilidad como en el del seguro obligatorio colombiano no desagrega los diferentes tipos de daños personales -los inherentes a su integridad biológica- que sufre la víctima $^{49}$ al ser valorados judicial o extrajudicialmente. A este respecto no hay una norma que permita individualizarlos y menos aún repararlos totalmente, es la jurisprudencia en las distintas jurisdicciones la que ha venido identificando las diferentes tipologías del daño, ausencia importante pues su categorización debería ocupar un lugar preferente en los temas de responsabilidad de la doctrina jurídico- económica y del Derecho de Daños, en demanda de acciones que prevean su justo reconocimiento y la adecuada satisfacción para los perjudicados ${ }^{50}$, más aún, cuando es sabido que nadie puede escapar a los riesgos derivados

49 Siguiendo principios de los sistemas anglosajones y los países de la Europa continental, hay un nuevo interés en la reparación de la víctima y la necesidad de reformar la legislación penal y civil, por ello un sector de la doctrina Alemana, califica el renovado interés por proteger la posición de la víctima, como un "redescubrimiento" y uno de los acontecimientos político-criminales más importantes de la última década. TAMARIT SUMALLA, Josep M. La reparación a la víctima en el derecho penal. Estudio y Crítica de las nuevas tendencias político-criminales. Barcelona: Fundació Jaume Callís, 1993, p 15, (en cita a SCHÖC, Heinz. Deustcher Juristentag- Gutachten. München: Beck, 1992, p 54.) Estas circunstancias llevaron a la necesidad de propugnar reformas legislativas de las anacrónicas leyes de responsabilidad civil extracontractual, positivadas en los ordenamientos de casi todos los países del mundo, en beneficio de la víctima para obtener reparación por parte del culpable o prever mecanismos de compensación en caso de insolvencia, antes que a centrar las acciones en dirimir la imputación -penalistadel presunto responsable.

50 SALVADOR CODERCH, Pablo., y CASTIÑEIRA PALOU, M ${ }^{\mathrm{a}}$ Teresa. Prevenir y castigar libertad de información y expresión, tutela del honor y funciones del derecho de daños. Madrid: Pons, 1997, p 133-161, señala en un aparte de su obra “(...) una crítica a la doctrina según la cual el derecho de daños persigue finalidades de prevención (de accidentes) puede basarse en la distinción entre justicia conmutativa 
del automóvil, ya sea como propietario, poseedor, conductor o simple sujeto pasivo del perjuicio consecuencial que entraña la creciente actividad de la conducción. Este sistema subsidiario que garantiza la reparación - sino total, por lo menos en parte- del daño personal ó corporal, en el Derecho colombiano, a diferencia del seguro español-S.O.A-, es un sistema de contratación forzosa a cargo del detentador del vehículo, para cubrir la totalidad de las personas que han sufrido daños en el accidente, la víctima que bien puede ser, el mismo conductor, el tomador de la póliza, sus familiares o terceros, siendo indiferente determinar por culpa de quién se ocasionó el "accidente".

Desde otra perspectiva, tales circunstancias de asegurabilidad en el SOAT, permiten deducir ex ante que estas características favorables a todas las víctimas, riñen con los postulados básicos de la responsabilidad civil y el aseguramiento de la misma, pues los institutos de responsabilidad civil, se consagraron para responder a terceros, atribuir la reparación del perjuicio causado a la víctima, y no para beneficiar al propio autor del daño (el conductor), que expresamente, en los contratos de seguro de responsabilidad civil excluye tal beneficio, tanto a favor de la víctima culpable y con mayor razón para el asegurado cuando la responsabilidad proviene de su dolo o culpa grave, pero que en el caso del SOAT está cubierta; todas estas distinciones, reafirman su naturaleza de ser un seguro de accidentes personales, acorde con su denominación gramatical como "seguro de daños corporales en accidente de tránsito" con el interés de indemnizar la muerte, incapacidad o los gastos de recuperación de las víctimas del accidente, proposiciones y finalidad innegables de la dogmática jurídica de los seguros de personas y totalmente extraña a los seguros de daños.

Igualmente, su consagración es atípica, en medio de la reglamentación de tránsito ${ }^{51,}$ (art. 96 C.N.T) y no en el Código de Comercio, que recoge las disposiciones del contrato de seguros (art. 1036 a 1.161), como contrato mercantil. En favor del sistema de asegu-

o correctiva y justicia distributiva [... ]la primera se limita a considerara las partes en litigio y trata de restaurar el equilibrio roto por el acaecimiento del daño, por la causación injusta de un mal; en cambio, la segunda trasciende la relación entre las partes y busca el bien de la sociedad, pues la situación del individuo es valorada en relación a los recursos de la sociedad e incluye la asignación de las pérdidas causadas por accidente al margen incluso de cualquier consideración de reproche"; lo que lleva a la necesidad de diseñar políticas públicas con soluciones o remedios públicos o privados.

51 En el Capítulo X del Código Nacional de Tránsito Terrestre se consagra el SOAT, "Art. 259.- Modificado. Ley 33 de 1986, art. 115. El seguro por daños a las persona causados en accidentes de tránsito será obligatorio y el perjudicado tendrá acción directa contra el asegurador". 
ramiento obligatorio, también la Suprema Corte, se pronunció inicialmente denominándolo equivocadamente a nuestro entender, como "un seguro de responsabilidad a favor de terce$r{ }^{\prime \prime}{ }^{52}$, pese a que, en verdad no es más que un típico seguro de accidentes personales con anexo de gastos sanitarios; pues en cuanto a los elementos estructurales señalada en la legislación comercial para los seguros de responsabilidad, nos permite decir que no comporta éste la técnica específica de ser un seguro de daños para protección del patrimonio del asegurado, puesto que al excluir la Ley del monto a reparar por responsabilidad, las prestaciones por los amparos de muerte e incapacidad permanente, el crédito de responsabilidad civil sigue estando a cargo del causante del daño y sólo las coberturas correspondientes a gastos médicos, funerarios y de transporte pueden ser deducidos de la totalidad del daño indemnizable o reembolsados a quien efectivamente los sufragó ${ }^{53}$

Igualmente, en el SOAT, no constituye exclusión, incluso el que el vehículo llegare a ser utilizado como arma, en cuyo supuesto se estaría en frente de un delito de homicidio o lesiones personales dolosas, con intensionalidiad, circunstancia que repele los principios orientadores de la responsabilidad civil y del Derecho de seguros en general por la cual se liberaría al asegurador obligatorio, puesto que el siniestro no tiene como causa el riesgo de la circulación, sino una actuación

52 C.S.J. Sentencia de Enero 29 de 1987. Fallo proferido acerca de la exequibilidad de los arts. 115 y 116 sobre vigencia del S.O.A.T., de la Ley 33/86, en el cual se declaró que "se trataba de un seguro de responsabilidad civil por daños a terceros". Ratifica así la Corte Suprema, que es un seguro de responsabilidad civil por daños a terceros, con beneficiario indeterminado, que hipotéticamente será determinable al momento del accidente - la víctima- legitimada para recibir la prestación del contrato, aunque entre en contradicción desde una perspectiva de lege ferenda con los principios básicos que estructuran los contratos de seguro de responsabilidad civil, al no poder deducir de la totalidad de la suma indemnizada por el S.O.A.T, en favor del agente dañador el conductor- o del tercero civil responsable, - propietario, administrador, usufructuario, etc.- las coberturas obligatorias de Muerte e Incapacidad permanente, al liquidar la totalidad de los daños causados. Y añadiríamos nosotros que la cobertura a favor del tomador, asegurado o conductor, también repulsa a la naturaleza de la institución de responsabilidad porque concurren en los extremos de víctima y obligados a reparar y con derecho a reparación por la ocurrencia del accidente de tránsito. Esta interpretación no la compartimos pues desde la dogmática del Derecho de seguros, la estructura y prestaciones lo determinan como un típico seguro de personas mixto o combinado: un seguro sanitario o de salud y de un seguro de accidentes personales, sometido totalmente a su régimen normativo. En fallos recientes se reconoció su verdadera naturaleza como un seguro de carácter socializado para cubrir los gastos personales del accidentado.

53 Cfr. Decreto 1032/91 del 18 de abril. Vid cita notas 7-8. 
dolosa en que el vehículo es el arma empleada, situación que sí se tipifica p.e en auténticos sistemas de responsabilidad como el del Derecho español y, es causal de no responsabilidad en el SOA.

En consecuencia de lo anterior, los elementos esenciales del SOAT colombiano y las prestaciones convenidas, con criterios prestacionales de solidaridad social, definen su naturaleza como un típico "Seguro mixto de accidentes personales y salud", clasificado dentro del ámbito de los seguros de personas y no en los seguros de daños, de acuerdo a la siguiente estructura:

1) El primero, con dos coberturas básicas de protección, indemnizables a la ocurrencia del riesgo como un seguro de accidentes personales:

a) Muerte accidental, siempre y cuando la causa derive de un acci- dente vehicular, sobre la vida del conductor, tomador, asegurado, familiares o amigos ocupantes del vehículo y terceros no ocupantes;

b) Incapacidad permanente por lesiones, para las mismas personas, por un monto limitado en la Ley.

2) En segundo lugar, un Seguro sanitario o de salud, con dos coberturas de carácter indemnizatorio destinadas al restablecimiento y recuperación de la salud, tanto para propio causante del daño, el conductor, sin distingo alguno de ser el tomador, asegurado o a los terceros, pasajeros o peatones.

a) Gastos médicos, quirúrgicos, farmacéuticas y hospitalarios

b) Gastos funerarios y;

c) Gastos de Transporte desde el sitio del accidente, hasta el límite de las coberturas ${ }^{54}$

A efectos de éstas coberturas se considera a todas las personas involucradas en el accidente como vícti-

$\overline{54}$ Cfr. Art. 11, Parágrafo del D. 1032 de 1991: “Las sumas pagadas por concepto de los amparos de carácter indemnizatorio de las pólizas que se emitan en desarrollo de este decreto, se entienden prioritarias e imputables a la indemnización que por mayor valor pueda resultar a cargo del responsable del accidente." La deducción que podemos hacer sobre los amparos indemnizatorios del S.O.A.T, es que efectivamente están destinados a recuperar la salud y proteger la integridad corporal de la víctima, enmarcados dentro de la concepción de daño patrimonial como los gastos de curación, sean quirúrgicos, farmacéuticos, hospitalarios, funerarios y de transporte, que por tener tal carácter se les reconoce como imputables a las indemnizaciones que por mayor valor pueda resultar a cargo del responsable del accidente.

Las indemnizaciones por Muerte e Incapacidad, como lo anotamos supra - nota anterior- no tienen tal consideración y no podrán deducirse del monto de la condena por R.C. Lo anterior es la base, que ha permitido a la jurisprudencia, erróneamente en nuestro concepto, definir tal cobertura del SOAT como de responsabilidad civil, repugnando tal estimación por que en esencia no se indemniza, ni se compensa nada, sólo se atiende a unos gastos mínimos de curación que mal pueden entenderse como reparatorios del daño causado en un accidente de tráfico, que entre otras cosas, suelen ser de gran magnitud. 
mas; por ser prestaciones de carácter patrimonial, se liquida la indemnización a favor de quien efectivamente asume el pago de los gastos y con los límites autorizados en el SOAT, que se reembolsan directamente a la clínica, hospital, o la persona que realizo el pago; siendo los únicos valores que pueden ser imputados a las prestaciones debidas de responsabilidad civil.

Ahora bien, teniendo en cuenta, que de los valores asegurados por el SOAT, con que el asegurador indemniza a la víctima o sus derechohabientes, las sumas por muerte e incapacidad permanente, no pueden ser deducidas de la indemnización que por responsabilidad civil se reclame judicial o extrajudicialmente al responsable del accidente, puede afirmarse que no procede tal deducción, al no tener tales coberturas carácter indemnizatorio, precisamente por su naturaleza de seguro de personas que al disponerlo así la legislación aplicable al Contrato de Seguro obligatorio ${ }^{55}$, estas constituyen, en consecuencia, una cobertura con finalidad social de reparación, impuesta por el Estado, quedando por abonar al crédito de responsabilidad, únicamente las sumas indemnizadas por gastos de curación, funerarios y de transporte, que son indemnizaciones limitadas y mínimas que en nada reparan el daño causado por responsabilidad civil automovilística, y puede afirmarse que estás también son coberturas de previsión social para solucionar los gastos de primeros.

No obstante la limitada cobertura del SOAT, puede concluirse que el aseguramiento obligatorio impuesto a todo vehículo en circulación, es un sistema que palia al menos en parte los resultados dañosos de los accidentes de tránsito en Colombia, y corresponde más a una solución extrajurídica de reparación, que disminuye los costes de la seguridad social y remedia en algo la demanda social de garantía, no sólo para los terceros - las víctimas- sino para el propio conductor, el propietario, asegurado o tomador, al considerarlos a "todos" como terceros con derecho a obtener la indemnización excluido en el caso de colisión de dos o más vehículos, en que cada conductor debe estar cubierto por su propio seguro y a su asegurador debe reclamar. En este seguro si bien, se contravienen principios básicos de la institución de responsabilidad civil extra-

\footnotetext{
55 Al definir el Art. 1140 del Código de Comercio, los “Amparos con carácter indemnizatorio" como aquellos que tienen un carácter de daño patrimonial, p.e. gastos médicos, clínicos, quirúrgicos y hospitalarios,, etc., que se regulan por las normas de los seguros de daños, quedando por fuera, en consecuencia, por ser extraños a tal naturaleza los amparos de Muerte e Incapacidad Permanente, que en tal caso al no tener el carácter de indemnizatorios, no pueden ser abonados a la indemnización a cargo del responsable del accidente. Vid sobre el carácter indemnizatorio de los seguros, la obra del insigne maestro colombiano OSSA, EFREN, Tratado Elemental de Seguros. Bogotá: Lerner, 1963.
} 
contractual $^{56}$, sí está ligado a la institución de responsabilidad sin culpa con la finalidad de reparar parte de los daños generados por el riesgo desplegado en la actividad automovilística, prescindiendo totalmente del elemento culpabilístico como requisito previo a la indemnización del daño corporal. De otra forma, nótese que al permitir por mandato legal, beneficiar en forma automática a todo aquel que sufre daños en el accidente de tránsito, se fortalece también los sistemas de previsión social por prestaciones de servicios sanitarios.

Es claro que en este esquema de garantía del Derecho colombiano, subyace, un interés jurídico de protección a la persona humana, a su integridad corporal como víctima ${ }^{57}$ y no a sus bienes o patrimonio, ni a los del asegurado, tomador o causante del daño, aunque sí se dirija a prever su insolvencia, al trasladar por el pago de una prima al contrato de seguro la liquidación del daño a cargo del asegurador, quien reparará de forma automática o concomitante a la ocurrencia del accidente, dada su verdadera esencia de indemnizar sólo el daño personal emergente, excluyendo el daño sobre bienes.

En cuanto a la cobertura y reparación de los daños a los bienes y al daño extrapatrimonial -como los daños morales o rentas por percibir- están excluidos de la cobertura del S.O.A.T; al igual que los daños personales cuyo valor exceda el límite del seguro, que es mínimo, para los cuales se debe perseguir su pago mediante el seguro voluntario u otras garantías establecidas en las leyes de responsabilidad civil o por la vías especiales u ordinarias del proceso penal o civil para per-

56 En la dogmática jurídica, en la institución de responsabilidad civil, no se puede tener al mismo tiempo la condición de tercero perjudicado y de causante, tomador o asegurado obligado a responder, o sea que no se puede obtener beneficio de la propia culpa o responsabilidad, situación que queda patente en el seguro obligatorio español y las directivas comunitarias que excluyen del ámbito del S.O.A, al conductor del vehículo causante del daño, contrario al SOAT en el derecho colombiano, que contrario a la naturaleza de la responsabilidad civil, denomina como tal al seguro obligatorio siendo que tanto su naturaleza como finalidad apunta a prever un sistema de salud con el cual se financie y paguen los gastos de atención médica, hospitalaria y de entierro de las víctimas diarias de accidentes de transito.

57 Favorecer la reparación del daño, es el tratamiento que se le ha querido dar desde 1985, cuando las Naciones Unidas, celebraron en Milán el VII Congreso sobre prevención del Delito y Tratamiento del Delincuente", se debatió un estudio sobre "la reparación, la asistencia, la restitución y la indemnización de las víctimas de delitos"; llegando a proponer a los Estados la creación de fondos nacionales de compensación a las víctimas, con mecanismos extrapenales para solucionar el conflicto entre autor y víctima, mediante procesos de mediación y conciliación con medidas de restitución y de compensación. TAMARIT SUMALLA, Josep M. La reparación a la Victima en el derecho penal. Estudio y crítica de las nuevas tendencias político-criminales. Barcelona: Fundació Jaume Callís, p 15/17. 
seguir los bienes del civilmente responsable. Por eso, surgen necesariamente, preguntas que trataremos de responder, en cuanto a la eficacia del aseguramiento obligatorio como por ejemplo ¿Sí son suficientes, para las víctimas, las indemnizaciones contenidas en la póliza de seguro obligatorio o debe este ser mejorado? ¿Si el sistema de responsabilidad civil y seguro debe integrar un solo cuerpo normativo?

Desde otro punto de vista, lo que también se deduce, es la oportunidad que reviste para la víctima la subsidiariedad de la garantía del seguro para la reparación del daño, trasladada, así sea en forma limitada, a un tercero solvente -el asegurador- que es quien paga la indemnización. También, somos conscientes de que indudablemente, a pesar de la existencia de las instituciones de responsabilidad y aseguramiento obligatorio del automóvil, son mayores los cuestionamientos, ante el amplio panorama de víctimas de la accidentalidad vial y de sus causas que aún no obtienen más que un mínimo grado de “reparación” por las vías judiciales, y de muchas más que ni siquiera acceden ante la administración de justicia o ante las empresas aseguradoras en acción directa para la liquidación de las indemnizaciones que por daños materiales corporales les ofrece el sistema de responsabilidad del S.O.A.T, bien por desconocer su alcance o incrédulos de la efectividad del sistema de responsabilidad en general ${ }^{58}$, con procesos lentos, donde la víctima tiene un trato casi marginal, ante el protagonismo y múltiples garantías de defensa del conductor, presunto responsable - en materia penal- sumado a las dificultades de vincular al tercero civil responsable que agregado a la situación de insolvencia o traspaso de bienes - en lo civil y/o penal-no garantiza una justa ejecución de la condena de reparación, haciendo desistir a muchos perjudicados de proponer la acción correspondiente, que de culminar, en el mejor de los casos, se convierte en un fallo ilusorio o disímil frente a casos equivalentes, dependiendo de la jurisdicción invocada y con remotas posibilidades de obtener del

58 Vid como referente social, lo publicado en el periódico EL ESPECTADOR.(1996) “iMejor arreglemos!". Noticias del 20 de septiembre, vía internet, www.elespectador.com, en la que se analizaba los resultados de un estudio del Ministerio de Justicia y del Derecho que al analizar los mecanismos vigentes para solución de conflictos derivados del accidente de tránsito, arrojó sorprendentes resultados, sobre la falta de credibilidad en la administración de justicia, pues el 98\% de los colombianos prefiere arreglar "por las buenas" antes que llamar a las autoridades para conciliar por vía judicial. Lo más significativo, es la incredulidad generalizada sobre las normas de responsabilidad por accidentes de tránsito, llegada al extremo que algunos propietarios de vehículos ni siquiera hacen efectivo el seguro de responsabilidad por accidentes, asumiendo costes directos, con tal de ahorrarse tiempo en querellas y trámites; prefieren el descuento por no reclamación, que se pactan en las pólizas, antes que a entablar pleitos. 
responsable, la reparación integra del daño ${ }^{59}$.

Por todo lo anterior, creemos en la importancia del tema y la necesidad de buscar a través de la investigación y su estudio con el Derecho comparado extranjero, en está oportunidad con el Derecho español y el Derecho comunitario europeo, el cumplimiento o no de los objetivos fijados en la dogmática jurídica y en las políticas judicial y legislativa, para lograr los fines de justicia, equidad y seguridad jurídica que debe cumplir todo sistema de responsabilidad civil por accidentes automovilísticos. De ahí la justificación, buscando respuestas respecto de nuestro ordenamiento y el comparado, que puedan ser atemperadas en la necesaria evolución del sistema tanto de la responsabilidad civil como del aseguramiento obligatorio por accidente de tránsito.

Finalmente las CONCLUSIONES que recogen las principales notas obtenidas del análisis jurídico, nos permiten afirmar que en Colombia, en la institución de responsabilidad civil, se conjuga un sistema de responsabili- dad "por actividades peligrosas" con inversión de la carga de la prueba y presunción de responsabilidad, que en nuestra opinión y de acuerdo a su construcción jurisprudencial se comporta como una responsabilidad cuasi objetivada, con exoneración de responsabilidad por una causa extraña, de fuerza mayor, caso fortuito, culpa de la víctima o de un tercero, con rasgos propios de un sistema de responsabilidad por riesgo con un mecanismo de garantía a través del aseguramiento obligatorio, que "socializa" las pérdidas a cargo de todos los propietarios de vehículos pero que es insuficiente.

En cuanto a la efectividad del sistema de garantías, el SOAT tiene una acertada estructura de cobertura sin culpa, propia de un sistema por riesgo, destinado básicamente a la atención sanitaria o de salud. Este es un seguro de no responsabilidad, un seguro mixto de accidentes personales y salud; que como tal debe seguir, pero evolucionando hacia unas coberturas más amplias que incluyan partidas por los daños morales y la totalidad de los gastos de curación. En cuanto a los

59 DE ANGEL YAGUEZ, Ricardo. "Sobre la eventual limitación de la cuantía de las indemnizaciones en daños personales derivados de la circulación". Documentación Jurídica, Madrid, 1995, núm. 81, p 138 y ss, respecto de la responsabilidad civil que encuentra su fundamento último en el principio de "la reparación integra del daño" y desde luego objetivo de toda indemnización, al poner de ejemplo la reparación integra en un caso de invalidez permanente dice: (...) es en el fondo un juego de palabras o una formulación retórica para dar cabida (o en la que como resultado se dé cabida) a una discrecionalidad judicial sin freno alguno. Discrecionalidad que, como se ha dicho por autorizada voz (VINEY), puede conducir a una fijación de indemnizaciones en función del sentimiento personal del juez, lo que lleva inevitablemente a una formidable desigualdad entre los justiciables". Concluyendo el autor, lo difícil de alcanzar la plena reparación por los daños causados a la víctima. 
perjuicios patrimoniales de lucro cesante, pérdidas de renta, etc., y el exceso de daños corporales materiales por lesiones graves e invalideces, no cubiertas por el SOAT, se debe seguir acudiendo al sistema tradicional de responsabilidad civil, por la jurisdicción penal o civil, para que dirima la responsabilidad y la prueba de la cuantía del resarcimiento de estos daños, bajo criterios de imputación de responsabilidad cuasi-objetivada, que se deben consagrar expresamente en una Ley de responsabilidad civil y seguro que incluya un método de valoración de daños de la vida humana y sus perjuicios extrapatrimoniales o daño moral, necesaria reforma del seguro obligatorio de accidentes automovilísticos en el Derecho Colombiano. Es importante incluir en los amparos indemnizatorios del SOAT, una cobertura para daños materiales a bienes de la víctima - casi siempre vehículos- supeditando esta partida a las normas de R.C, que reconocida extrajudicial o judicialmente la responsabilidad del tomador $o$ asegurado, se haga efectiva. Modificación viable, dada su técnica legislativa, y considerando que a sí lo ha reconocido la jurisprudencia nacional de ser un seguro de responsabilidad civil a favor de terceros - aunque sea una interpretación equivocada que no compartimos - pus si bien no incluye actualmente en sus coberturas, daños a bienes (o daños materiales) propios o de terceros, estos quedan por fuera de su órbita de protección y regulación, bien valdría, aceptada la naturaleza que le ha asignado la jurisprudencia, de ser un estricto seguro de responsabilidad, para que se adopte un límite medio de indemnización a bienes, por el cual se repare los daños de vehículos de terceros- que constituyen en las reclamaciones por accidentes automovilísticos, una alto porcentaje, lo que a su vez reflejan el elevado número de vehículos sin seguro voluntario de automóviles para la reparación por colisión.

Como resultado final ${ }^{60}$, se aspira a que este estudio se convierta en una propuesta de reflexión para los operadores jurídicos del sistema de responsabilidad civil automovilística, jueces, abogados, asegurados, aseguradores, y en un futuro cercano, sirva de aporte para el diseño de las necesarias reformas que el legislativo debe emprender especialmente en cuanto a los criterios de imputación y la valoración y reparación de la integridad del daño corporal, que beneficie a tomadores, asegurados, terceros afectados y com-

60 Debe aclararse que ésta investigación es apenas el principio de un proyecto que como docente de la Universidad del Valle en las cátedras de Derecho de responsabilidad civil y miembro del Instituto de Responsabilidad Civil extracontractual y del Estado continuaré en el tiempo, particularmente en el ámbito de las políticas y la legislación de reparación y valoración del daño corporal. Como colofón final, no se agotan aquí todas las posibilidades de estudio de la responsabilidad civil automovilística, particularmente en lo relativo al ámbito de la reparación del daño corporal, pero sí, las más sensibles dentro de la dogmática jurídico-civil. 
pañías de seguros, sujetos sobre los que repercute la efectividad de las normas reguladoras de la responsabilidad civil del automóvil del derecho de accidentes o del derecho de daños, cuyos fines, son los sistemas de compensación y de prevención. que demanda de acciones urgentes de protección y prevención mediante la implementación de políticas públicas ante la creciente accidentalidad que en la actualidad, a la par de no ofrecer reparaciones satisfactorias a las numerosas víctimas por el sistema de administración de justicia, también congestiona y desperdicia cuantiosos recursos públicos y privados en los despachos judiciales y, que tampoco suple el sector asegurador, ante el creciente mercado de potenciales asegurados que demandan mayores niveles de protección por responsabilidad del automóvil a través de mejores pólizas de seguro obligatorio, con normativas eficaces que impongan verdaderas coberturas de responsabilidad civil automovilística y no meros contratos de atención sanitaria o de salud que dejan sin reparación las secuelas fisiológicas y económicas del daño.

Se anticipa, como resultado esperado, que este estudio pueda ser publicado para conocimiento de los interesados en el estudio de la responsabilidad civil automovilística y propicie en el Derecho colombiano la reforma del sistema de responsabilidad y de su seguro obligatorio del automóvil, incluso ante la evolución del tráfico mercantil asegurativo, un estatuto, por fuera del Código de Comercio, destinado a especialmente a la legislación de contrato de seguro, y otra, que valore la vida humana y tasé cualquier forma de daño, incluido el moral o extrapatrimonial que la persona sufra para ser aplicada en cualquier ámbito de la responsabilidad en general para todo tipo de causación de daños.

\section{Bibliografía}

Así es el Valle del Cauca. Colombia. Periódico El país, Cali, 1998, p 23

BISBAL, JUAQUIN "El coste de los accidentes. Análisis económico y jurídico de la responsabilidad civil”. Barcelona: Ariel, 1984, p7

CARLOS ALBERTO, Tratado TécnicoJurídico sobre Accidentes de Circulación y materias afines. $4^{\mathrm{a}}$ ed. Santafé de Bogotá: Liberia el Profesional, 1996, 794p

CÁCERES CORRALES, PABLO J. "Critica constitucional. Del Estado liberal a la crisis del Estado providencia. Bogotá: Banco de La república- p 1719

CALABRESI, GUIDO. The Cost of Accidents (A Legal and Economic Analysis). Trad. de Joaquín Bisbal. Barcelona: Ariel, 1984

DE ÁNGEL YAGÜEZ, RICARDO. $A l$ gunas previsiones sobre el futuro de la responsabilidad civil (Con especial atención a la reparación del daño). Madrid: Civitas, 1995, $241 \mathrm{p}$

DE ÁNGEL YAGÜEZ, RICARDO. "Sobre la eventual limitación de la cuantía de las indemnizaciones en daños personales derivados de la circulación". En Documentación Jurídica, Madrid, 1995, núm. 81, p. 127- 170

DE ÁNGEL YAGÜEZ, RICARDO. "Evaluación del perjuicio corporal en derecho común de la responsabilidad. Los 
terceros pagadores". Revista Española de Seguros, Madrid, 1988, núm. 56

DURÁN Y LA LAGUNA. Una aproximación al análisis económico del derecho. Granada: Comares, 1992, 209 p.

DURÁN Y LA LAGUNA. EL ESPECTADO. (1996) ";Mejor arreglemos!". Noticias del 20 de septiempre, via internet.

ESPITIA, VICTORIA EUGENIA. "Accidentalidad epidemia de indisciplina", en Salud Coomeva, 2000, p 12-13

ESPITIA, VICTORIA EUGENIA. Gaceta judicial N 1934 y 1936.

GABALDON GARCÍA, JOSÉ LUIS. "Caracterización y privilegios sobre el buque". Anuario de Derecho Maritimo, Vol. XII, 1995, p 239

GALINDO, JORGE ALBERTO. "El alcohol y la accidentalidad vial", en $R e-$ vista Fasecolda, № 88, abril-junio, 1998, p 37-39

"Accidentalidad vial en Colombia. Como prevenirla”, en Revista Fasecolda, $n^{\circ} 81$, septiembre 1996

GÓMEZ POMAR, FERNANDO. "El derecho de accidentes y el análisis económico: Presupuestos e implicaciones básicas", en AA.VV.: Análisis económico del derecho y de la política, Santiago de Compostela, Fundación Alfredo Brañas, 1993, pág.. 83-99.

GÓMEZ, FERNANDO y PASTOR, SANTOS. "El derecho de Accidentes y la responsabilidad Civil. Anuario de Derecho Civil, tomo XLIII, fascículo II, abril-junio, 1989, p 495- 537.

ILLESCAS RUS, ANGEL VICENTE. "La cobertura obligatoria de los daños y perjuicios ocasionados por vehículo dirigido por conductor no autorizado". En Documentación jurídica, Madrid, 1995, núm. 81, p 281- 349

ILLESCAS RUS, ANGEL VICENTE. " $E l$ $<<$ sistema para la valoración de los daños causados a las personas $>>$ de la Ley sobre responsabilidad civil y seguro en la circulación de vehículos a motor: ventajas y problemas", ponencia en Jornada Jurídica sobre la Responsabilidad Civil y la valoración del daño corporal, Madrid, 25 de marzo de 1998

"Los baremos vinculantes en daños corporales". En Revista de Responsabilidad Civil, Circulación y seguro, 1995

MARTÍNEZ RAVE, GILBERTO. La Responsabilidad Civil Extracontractual en Colombia. $7^{\mathrm{a}}$ ed. Medellín: Dike, 1993 , P 11 y $9^{a}$ ed. Medellín: Dike, 1996, p 318- 323.

MEDINA CRESPO, MARIANO. $\mathrm{El} \mathrm{se-}$ guro obligatorio de automóviles. Madrid: Lerko, 1994, p 217

MORILLAS JARILLO, MARÍA JOSÉ. "La valoración de los daños: El baremo". En Documentación Jurídica, Coloquios sobre la responsabilidad civil del automóvil, Madrid, núm. 81, p. 205- 208

OSSA, EFREN, Tratado Elemental de Seguros. Bogotá: Lerner, 1963

PANTALEÓN PRIETO, FERNANDO. "Los baremos indemnizatorios en la valoración de los daños a las personas". Documentación jurídica, Madrid, 1995, núm. 81, p 171- 204

PASTOR PRIETO, SANTOS. Sistema Jurídico y Economía. Una introducción al Análisis Económico del Derecho. Cap. VII. Madrid. Tecnos, 1989, p155 PERDOMO M, MÓNICA ESPERANZA. "Muertes por accidente de tránsito", en Forensis 2000. Datos para la Vida, septiembre 2001, p 144-165.

PINTOS AGER, JESÚS. Responsabilidad civil y reparación sin culpa....op.cit., $\mathrm{p}$ 432; del mismo autor Baremos, seguros $y$.... p 337 
PINTOS AGER, JESÚS. Baremos, seguros y derecho de daños. Madrid: Instituto de Derecho y Economía- Universidad Carlos III de Madrid, 2000, p 25-35

PINTOS AGER, JESÚS. Baremos, seguros y ...op.cit., $\mathrm{p} 40$

PINTOS AGER, en su obra Baremos, seguros y ...op.cit, p 34

PERDOMO M, MÓNICA ESPERANZA. "Muertes por accidente... op.cit., p 144-165 (publicación del Instituto de Medicina Legal y Ciencias Forenses, Fondo de Prevención Vial)

PUY FRAGA, PEDRO. ET.AL. Análisis económico del derecho y de la politica. Santiago de Compostela: Universidad Internacional do Atlántico, 1993, 224 p.

SÁNCHEZ CALERO, FERNANDO. Comentarios a la Ley de Contrato de Seguro. Art.76. Madrid: Edersa, 1985, p 660

SÁNCHEZ CALERO, FERNANDO. Curso del derecho privado. Bilbao: Sever, 1961, p 6

SALVADOR CODERCH, PABLO, y CASTIÑEIRA PALOU, $M^{a}$ TERESA. Prevenir y castigar libertad de información y expresión, tutela del honor y funciones del derecho de daños. Ma- drid: Pons, 1997, p 133- 161

SHÖC, HEINZ. Deustcher Juristentag Gutachten. München: Beck, 1992, p54

TAMARIT SUMALLA, JOSEP M. $L a$ reparación a la víctima en el derecho penal. Estudio y Crítica de las nuevas tendencias político - criminales. Barcelona: Fundación Jaume Callís, 1993, P15

TAMAYO JARAMILLO, JAVIER. Tratado de Responsabilidad Civil, t. 2, Bogotá: Temis, 1999, 350 p.

TIRADO SUÁREZ, FRANCISCO JAVIER. "La adaptación del seguro del automóvil español a la normativa comunitaria (segunda parte)" en Revista Española de Seguros, $\mathrm{n}^{\circ}$ 49, p 73 y ss.

TIRADO SUÁREZ, FRANCISCO JAVIER. Directrices de la Comunidad Económica Europea sobre seguros. Madrid: UNESPA, 1979, $269 \mathrm{p}$

VENTURI, AUGUSTO. Los fundamentos cientificos de la seguridad social. Madrid: Ministerio del Trabajo y Seguridad Social, 1995, p 388- 401

XIOL RÍOS, JUAN ANTONIO. "Reflexiones sobre el sistema de valoración tasada del daño corporal causado con motivo de la conducción de vehículos de motor". Ponencia presentada en la misma Jornada Jurídica). 